\title{
What hides behind the German labor market miracle? Unemployment insurance reforms and labor market dynamics
}

\author{
Benjamin Hartung* Philip Jung ${ }^{\dagger} \quad$ Moritz Kuhn ${ }^{\ddagger}$
}

November 2018

\begin{abstract}
A key question in labor market research is how the unemployment insurance system affects unemployment rates and labor market dynamics. We revisit this old question studying the German Hartz reforms. On average, lower separation rates explain $76 \%$ of declining unemployment after the reform, a fact unexplained by existing research focusing on job finding rates. The reduction in separation rates is heterogeneous, with long-term employed, high-wage workers being most affected. We causally link our empirical findings to the reduction in long-term unemployment benefits using a heterogeneous-agent labor market search model. Absent the reform, unemployment rates would be $50 \%$ higher today.
\end{abstract}

JEL-Classification: E24, J63, J64

Keywords: Unemployment insurance, labor market flows, endogenous separations

${ }^{*}$ University of Bonn

${ }^{\dagger}$ TU Dortmund and IZA

${ }^{\ddagger}$ University of Bonn, CEPR, and IZA 


\section{Introduction}

A key question in labor market research is how the unemployment insurance (UI) system affects unemployment rates and labor market dynamics. We revisit this old question and provide new answers based on an analysis of one of the largest UI reforms in industrialized countries in recent decades: the German Hartz reforms. Economists have extensively studied how changes in the UI system affect job finding rates of the unemployed (unemployment outflows) either through their incentive effects on workers to search for new jobs (Katz and Meyer (1990) and Schmieder and Von Wachter (2016)) or through their incentive effects on firms to post new vacancies (Millard and Mortensen (1997), Krause and Uhlig (2012)). ${ }^{1}$ In this paper, we scrutinize the existing focus on job finding rates and draw attention to separation rates into unemployment (unemployment inflows). While the link between separation rates and the UI system is known in theory, little is known about its quantitative importance (Tuit and van Ours (2010)). The goal of this paper is to fill this void.

The Hartz reforms in Germany took place in the mid-2000s. At the heart of the reform was a change in the UI system that abolished long-term, wage-dependent unemployment benefits. We document based on social security microdata that $76 \%$ of the changes in German unemployment rates after the reform resulted from changes in separation rates and that changes in job finding rates only account for the remainder. We provide a first link between the UI reform and changes in labor market dynamics by documenting that the heterogeneity in the reform-induced reductions in benefit eligibility is also mirrored in the reduction in separation rates across workers. We find the largest reduction for long-term employed, high-wage workers. In a second step, we explain and causally link our empirical findings to the UI reforms using economic theory. Our results explain two key aspects of the German labor market miracle: notoriously high unemployment rates that are cut in half within less than a decade and a small increase in unemployment during the financial crisis. Theory and empirics jointly point to the important role of changes in separation rates as an adjustment channel after changes in the UI system.

Alternative narratives told so far about the Hartz reforms and the German labor market miracle have looked at job finding rates as the key margin of adjustment, either by

\footnotetext{
${ }^{1}$ The existing literature on job search incentives builds on theoretical grounds on the large literature studying the (optimal) design of UI systems. This literature focuses on the trade-off between providing insurance and the cost of additional unemployment due to reduced search effort (Baily (1978), Shavell and Weiss (1979), Hopenhayn and Nicolini (1997), and Chetty (2006)). Recently, there has been renewed interest in quantifying the incentive effects for firms' vacancy postings in relation to changes in UI benefits during the Great Recession in the United States (Hagedorn et al. (2016), Chodorow-Reich and Karabarbounis (2016)).
} 
highlighting changes in search effort (Krebs and Scheffel (2013)), changes in matching efficiency (Launov and Wälde (2013), Hertweck and Sigrist (2015) and Klinger and Weber (2016)), or changes in vacancy posting behavior (Krause and Uhlig (2012)). All of these narratives explain the decline in unemployment by an increase in outflows from unemployment. Our findings provide an upper bound for the contribution of these explanations. Understanding the relative importance of different adjustment channels after a UI reform is not merely of academic interest to better understand the workings of the labor market, but also implies very different welfare effects for different subgroups of workers in the labor force. We show that the current reform has resulted in substantial welfare losses for the large group of long-term employed, high-wage workers. Our narrative can therefore provide one potential explanation for the widespread discontent with the reforms among the German electorate despite the massive reduction in unemployment rates.

For our empirical analysis, we rely on social security microdata of individual employment histories in West Germany from the employment panel of integrated employment histories (SIAB). We construct worker-flow rates for one decade before and after the Hartz reforms and find that separation rates declined by $28 \%$ after the reform, while job finding rates increased by only $13 \%$. As a consequence, changes in separation rates account for $76 \%$ of the German labor market miracle. We demonstrate that this stylized fact is robust to a wide range of sensitivity checks and is also found using alternative data sources. The average decline in separation rates hides a lot of heterogeneity. We exploit the institutional setting that cuts in the generosity of benefits brought about by the reform were staggered by age, employment duration, and wages. We find correspondingly, in line with a causal effect of the reform, that after grouping workers by age, employment duration, and wages, it was the long-term employed, high-wage workers who reduced separation rates by up to $60 \%$, while low-wage, short-term employed workers show a comparatively modest decline of $20 \%$ in their separation rates after the reform. In a recent study, Jäger et al. (2018) explore a staggered extension of UI benefit durations by age on older male workers in Austria. In line with our findings, they find large increases in separation rates due to increased benefit generosity.

In our theoretical analysis, we develop a labor market search model with worker heterogeneity, aggregate fluctuations, and endogenous separation decisions to establish a causal link from the UI reform to changes in labor market dynamics. Workers in the model differ in their employment status, skills, job duration, wages, and UI benefit eligibility. Worker skills increase with job duration. An individually efficient bargaining protocol over wages and separation decisions then implies that high-skill workers are also high-wage workers in stable jobs. Our model incorporates key institutional features of Germany's UI benefit eligibility rules with respect to the dependence on employment 
duration and wages as in Krause and Uhlig (2012). ${ }^{2}$ We allow a UI reform to affect labor market dynamics via three channels: workers' incentives to search and accept job offers, firms' incentives to post vacancies, and the decision of workers and firms to separate. We calibrate the model to the pre-reform period and introduce the Hartz reform by abolishing long-term wage-dependent benefits. After the reform, the model matches closely the observed time series for average separation and job finding rates. To tighten the causal link from the UI reform to observed changes in labor market dynamics, we explore a range of additional model predictions linked to the UI reform. First, we study the heterogeneous effects of the reform on labor market participants and show that the model matches the heterogeneous responses closely. In the model, as in the data, the long-term employed, high-wage workers are most adversely affected. Second, we perform counterfactual simulations of the German labor market in the absence of the reform. We find that the reform also explains a second aspect of Germany's labor market miracle, namely, the good performance during the financial crisis when other labor markets experienced skyrocketing unemployment rates. In the absence of the reform, our model predicts that German unemployment rates would have skyrocketed as well during the financial crisis of 2008 and would have been 50\% higher today. We also show that the German unemployment rate would have, without the reform, closely tracked the labor market experience of Germany's close neighbor, Austria, supporting the validity of our quantitative predictions. Third, we provide empirical evidence that workers traded off wages against job stability to avoid separations into unemployment, in line with the theoretical mechanism. In a final step, we use the model to explore the welfare consequences of the UI reform. We find that the long-term employed, high-wage workers experienced large welfare losses in the absence of any government compensation.

In the model, a UI reform affects workers' search incentives, firms' incentives to post vacancies, and separation decisions. A crucial question is how to discipline the relative importance of these three different adjustment channels. In theory, there is a tight link between aggregate labor market fluctuations from productivity fluctuations and the responsiveness to changes in UI benefits (Costain and Reiter (2008)). Through the lens of the model, productivity changes and benefit changes both directly affect the value of employment relative to the outside option and are like two sides of the same coin. We therefore calibrate the model to be consistent with business-cycle moments for separation rates and job finding rates before the Hartz reforms. In this way, we tie our hands re-

\footnotetext{
${ }^{2}$ We share several modeling choices with Krause and Uhlig (2012), but differ in focus. Their findings and calibration strategy focus on changes in job finding rates through effects on vacancy postings rendering separation rates effectively exogenous in their quantitative analysis. Their model also does not include aggregate fluctuation to impose discipline on the elasticity of separation and job finding rates, which we exploit for the calibration as described below.
} 
garding the responsiveness of labor market flows to the UI reform. For the responsiveness of workers' search behavior, we target existing estimates on the elasticity of the search intensity to changes in UI benefits from the empirical literature. ${ }^{3}$ Our calibration only targets unconditional moments of worker-flow rates, but matches well the time series of labor market flows before the reform, thereby providing support for the model mechanism. After the reform, the model still matches the time series of labor market flow rates very closely, lending support to the independently calibrated elasticities. Matching both the time series and cross-sectional heterogeneity of changes in separation rates offers important evidence in favor of a causal link from the UI reform to the observed changes in labor market dynamics.

We use the calibrated model to ask the counterfactual question: what would have happened to the German labor market absent the Hartz reforms? The counterfactual simulations provide striking results. German unemployment rates would not have fallen over time, would have skyrocketed during the financial crisis as in most other industrialized countries, and would today be $50 \%$ higher than observed. This counterfactual simulation also provides a way to decompose changes in unemployment between 2004 and 2014, from the trough of a recession to a long-lasting boom. We find that business cycle dynamics account for at most $10 \%$ of the decline in unemployment rates, leaving most of the changes to the structural reform. We validate our counterfactual analysis relying on ideas inspired by the literature using control groups to identify and quantify the causal effects of policy interventions. In the spirit of such an approach, we consider Austria, Germany's close neighbor, as our control group that did not reform its UI system. Comparing counterfactual unemployment rates for Germany and Austria, we again obtain results that are striking. Absent the reform, our model predicts that the German and Austrian unemployment rate would have evolved in lockstep over the two decades under consideration. In the case of the reform, unemployment rates diverge strongly after the implementation of the reform providing further evidence for the causal impact of the UI reform on labor market dynamics. A final prediction of the theoretical model we explore is that, in the model, workers trade off wages against job stability in response to the reform. In particular, high-wage workers are willing to accept wage cuts in exchange for lower separation rates. In the data, we find evidence that such a trade-off took place.

In a final step, we use our microfounded framework to quantify the welfare effects from the reform for different labor market participants. We consider welfare effects abstracting from compensating transfers that the government could finance due to the lower spending

\footnotetext{
${ }^{3} \mathrm{~A}$ broad empirical consensus has emerged suggesting that this effect is modest. Typical estimates find that granting one additional month of UI benefits leads to 0.15 more months of unemployment (Chetty (2006), Schmieder and Von Wachter (2016)).
} 
on UI benefits after the reform. Put differently, we quantify how a transfer system needs to be designed to receive the support of the electorate. This question is key when it comes to the political feasibility of UI reforms. We find that losses amount to $2.11 \%$ in terms of consumption equivalent variation for the recipients of unemployment assistance benefits. Unemployment assistance benefits represent the long-term wage-dependent benefits that have been abolished by the reform so that the large welfare losses for workers in this group ought to be expected. Probably, these losses also explain the widespread grandfathering rules and hardship regulation that accompanied the reform and that were targeted to this group. Among the employed, we find the largest welfare losses among the long-term employed, high-wage workers. We find that their consumption equivalent variation to forgo the reform amounts to $0.64 \%$. Long-term employed workers account for almost two-thirds of the German labor market and the fact that their separation rates are the lowest among the employed might suggest that these workers are very detached from any changes in the UI system. Yet, we show that this is not the case and that in hindsight their large welfare costs might explain the widespread discontent among the electorate with the reform.

Two potentially important policy implications for labor market and social security reforms arise from our findings. The first relates to UI reform proposals in other European countries taking the Hartz reforms as a role model. Regarding the political feasibility of such reforms, our findings imply that appropriate compensation schemes have to be designed to avoid discontent in large parts of the electorate, as in the German case among the long-term employed, high-wage workers. Our model suggests a quantitatively important role for changes in separation rates in most European countries in line with findings in Elsby et al. (2013) and therefore welfare costs among the employed ought to be expected. By contrast, UI reforms in the United States will likely show the largest reaction in job finding rates. The theoretical justification for this conjecture comes from the crosscountry analysis in Jung and Kuhn (2014). Second, the strong reaction of separation rates after changes in nonemployment benefits suggests that similar reactions should also be expected and taken into account when evaluating other social security reforms such as early retirement programs or disability insurance programs that are widely discussed in Germany and elsewhere.

The remainder of the paper is structured as follows: we next provide a short description of the Hartz reforms. In Section 2, we describe our data and present the empirical results. We describe the labor market search model in Section 3. Section 4 shows the model results and discusses the counterfactual analysis. Before we conclude in Section 5, we discuss alternative explanations for the German labor market miracle in light of our empirical results. 


\subsection{The Hartz reforms}

In 2002 the German government entrusted an expert commission consisting of various representatives from business, unions, and academia with the task of working out reforms for the German labor market. The chairman was Peter Hartz, at that time director of human resources at Volkswagen. The subsequent reforms are commonly referred to as Hartz reforms. ${ }^{4}$ The main focus of the reforms was to restructure the federal employment agency and to enhance the matching process of unemployed workers to jobs. The ensuing reforms were enacted in four separate legislative packages commonly referred to as Hartz $I$ to Hartz IV between 2003 and 2005..$^{5}$ They consisted of comprehensive measures to promote and challenge the unemployed - ranging from subsidies for self-employment to the restructuring of the unemployment benefit system and a tighter supervision of benefit recipients. ${ }^{6}$ We provide further details in Appendix A.

In the next section, we provide empirical evidence that points toward a causal mechanism associated with the fourth step of the reform package (Hartz IV). In that step, the former three-tier system of unemployment benefits, unemployment assistance, and subsistence benefits was transformed into a two-tier system of unemployment and subsistence benefits. The reform constituted a substantial overhaul of the German UI system and implied a drastic cut in benefits for long-term employed workers who, before the reform, were eligible for long-term, wage-dependent unemployment assistance. After the reform, they only received subsistence benefits once unemployment benefits expired. We will focus on exploring the causal link from the unemployment insurance system to labor market dynamics and the unemployment rate in our structural model below.

\section{Data and empirical results}

This section introduces the microdata we use to analyze changes in unemployment rates and labor market flows. We demonstrate that the microdata matches the macroeconomic trends and explain how we adjust for administrative changes that otherwise impede a consistent measurement over time. In the second part, we present empirical results on changes in labor market flows and document large heterogeneity in these changes.

\footnotetext{
${ }^{4}$ The official title of the commission was the Commission for Modern Labor Market Services.

${ }^{5}$ The official title of the acts were First, Second, Third and Fourth Act for Modern Labor Market Services.

${ }^{6}$ Steffen (2008) provides a detailed chronicle of the German social security system.
} 


\section{$2.1 \quad$ Data}

Our main data source is the microdata on individual employment histories from the employment panel of integrated employment histories (SIAB) provided by the Institute for Employment Research (IAB) for the period 1975 to $2014 .^{7}$ The SIAB is a $2 \%$ representative sample of administrative data on all workers who are subject to social security contributions and on all unemployed workers in Germany. It excludes self-employed and civil servants, thus covering approximately $80 \%$ of Germany's labor force. Apart from its large size (1.8 million individuals) and its long panel dimension (up to 40 years), one further advantage of the administrative data is that they are virtually free of measurement error for the variables of interest in this paper. The data are taken from social security records and are merged with records on unemployment periods from the federal employment agency. The data contain the exact start and end dates of each employment and unemployment spell. In total, the data comprise almost 60 million individual spells. See Antoni et al. (2016) for further details on the data and its construction.

\subsection{Sample selection, construction of worker flow rates, and in- flow correction}

We restrict our sample to workers in West Germany and exclude marginal employment in our benchmark sample. We drop a few individuals with missing information on employment status or missing geographic information, and all individuals who only receive social assistance benefits while in the sample. We consider the effect of including marginal employment and looking at East and West Germany as part of our sensitivity analysis.

The data contain daily employment history information and we follow Jung and Kuhn (2014) to aggregate daily labor market histories to histories at monthly frequency. We assign monthly employment spells based on a reference week within each month. We report as separation rate the share of employed workers entering into unemployment from one month to the next and as job finding rate the share of unemployed workers entering into employment between months. We assign these employment state in the reference week following a hierarchical ordering where employment supersedes unemployment and unemployment supersedes out of the labor force. This approach closely follows labor force surveys such as the Current Population Survey (CPS). We count workers as employed if they are employed full or part time or work as apprentices. For the unemployed, we count workers as unemployed if they are registered as unemployed at the employment agency,

\footnotetext{
${ }^{7}$ We use the weakly anonymous Sample of Integrated Labour Market Biographies (SIAB) 1975-2014. The data were accessed on-site at the Research Data Centre (FDZ) of the Federal Employment Agency (BA) at the Institute for Employment Research (IAB) and via remote data access at the FDZ.
} 
which requires that they are not working and are actively looking for a job. Registration is required to be eligible for unemployment benefits. The German unemployment insurance system distinguishes between unemployed workers and benefit recipients. In the microdata, reliable information on the registered unemployment status is available from 2000 onward. We use this information to assign employment states. We assign employment states for earlier periods based on records of benefit recipient status. After computing worker flow rates based on benefit-recipient status before 2000, we construct growth rates of these worker flow rates and use them to extend the registration-based flow rates backward. This leaves the dynamics of the flow rates unaffected but removes the level differences between the two definitions. We provide further details on the construction of monthly employment states and transition rates in Appendix B. For our empirical analysis, we focus on the decade from 1993 to 2002 to document worker flows before the first reform steps were implemented. We report the entire time series of worker flows for the period after the reform but take the time from 2008 to 2014 as the period when the transition period after the reform was completed.

The goal of our empirical analysis is to study the changes in labor market dynamics that determine the evolution of the unemployment rate. In the first step, we demonstrate therefore that the microdata match the reported trends on unemployment rates. The microdata do not include public servants (Beamte), and hence, for the microdata to be comparable to the unemployment rates reported in the statistics of the German employment office, public servants have to be included. Figure 1(a) shows the unemployment rate for West Germany as reported by the German federal employment agency and the unemployment rate constructed from the SIAB microdata for the period between 1993 and 2014. The data from the German employment office cover dependent employment only and therefore exclude self-employed workers. ${ }^{8}$ Both unemployment rates track each other closely in trends and levels. We conclude that the microdata are consistent with developments in the unemployment rates and can hence be used to study the underlying changes in labor market dynamics. In Appendix B, we provide further discussion and demonstrate that the constructed worker flow rates in a stock-flow model account for the dynamics of the unemployment rate over time.

The data show a large spike in unemployment in January 2005. The reason for the spike is regulatory changes as part of the Hartz reforms that became effective in January 2005. These regulatory changes required all nonemployed who are able to work to register as unemployed to remain eligible for UI benefits. This caused an inflow of former social

\footnotetext{
${ }^{8}$ The German employment office reports two unemployment rates: one including all employees and one for employees in dependent employment, excluding the self-employed. We consider the unemployment rate for dependent employment.
} 
Figure 1: German unemployment rates (1993 - 2014)

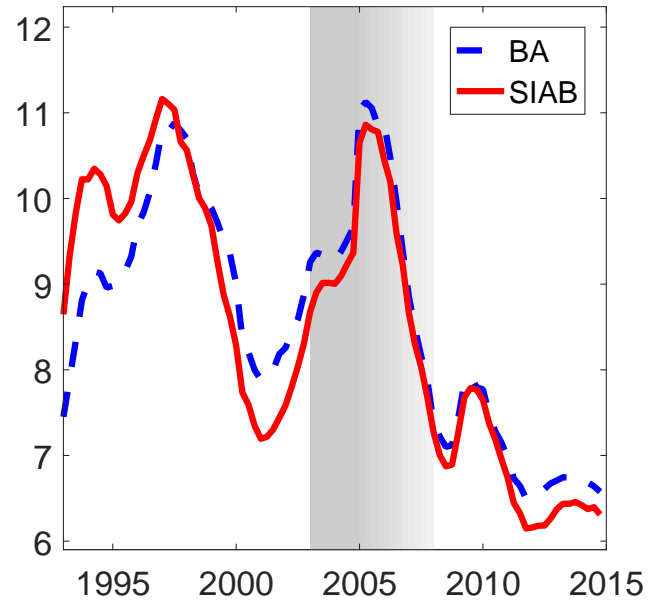

(a) BA and SIAB

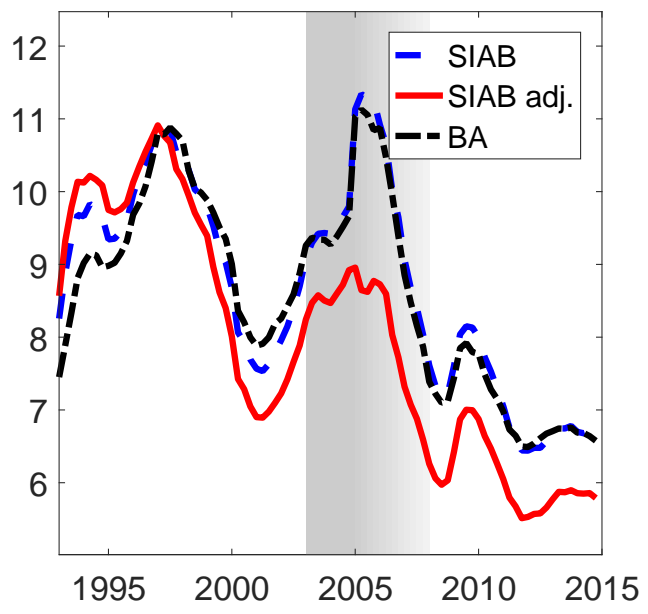

(b) SIAB with inflow correction

Notes: Unemployment rate for West Germany 1993 - 2014 in percent. Left panel: Blue dashed line shows reported unemployment rate by employment agency (BA) and red solid line shows the unemployment rate from SIAB microdata including imputed numbers for public servants not covered by the microdata. Right panel: Shows unemployment rate from SIAB microdata and employment agency as in the left panel (blue and black dashed lines) and the unemployment rate from SIAB microdata after inflow correction (red solid line). See text for details. The grey area marks the period 2003 to 2005 when the Hartz reforms were enacted. The fading out indicates the first transition years 2006 to 2008 after the reforms. Data are quarterly averages of monthly rates.

assistance recipients and spouses of unemployed into the unemployment pool and poses a challenge to a consistent measurement of worker flows before and after the reform of the UI system. The affected persons were mainly individuals who were much less attached to the labor market than the previously registered unemployed (see Table 1). We propose what we refer to as inflow correction for constructing comparable and consistent transition and unemployment rates over this period.

The key challenge is that we cannot directly observe either of the two groups that were forced to register as unemployed to retain their unemployment benefit eligibility. We therefore exclude persons who simultaneously satisfy three conditions: (1) entered unemployment in the first six months ${ }^{9}$ of 2005, (2) had a nonemployment spell before registering as unemployed, and (3) did not work for at least one month until the end of 2006. We compare in Table 1 the characteristics of new entrants into unemployment from out of the labor force in January 2004 and January $2005 .{ }^{10}$ We find large differences

\footnotetext{
${ }^{9}$ There is evidence that administrative problems and incomplete data records during the transition period make the records for the affected group in the first months after the reform less reliable.

${ }^{10}$ Out of the labor force is not directly observed in the data and we assign out of the labor force as a residual employment state to nonemployed workers who have intermittent nonemployment spells that
} 
Table 1: Worker characteristics of entrants into unemployment

\begin{tabular}{lccccc}
\hline & \multicolumn{3}{c}{ entrants from N } & \multicolumn{2}{c}{ other U } \\
\cline { 2 - 6 } & $2004-01$ & $2005-01$ & $2005-01$ (corr.) & $2004-01$ & $2005-01$ \\
\cline { 2 - 6 } female & $43.3 \%$ & $60.9 \%$ & $45.8 \%$ & $41.1 \%$ & $42.1 \%$ \\
age & 36.9 & 37.3 & 36.0 & 40.9 & 40.9 \\
high school & $23.2 \%$ & $44.2 \%$ & $32.5 \%$ & $16.6 \%$ & $18.8 \%$ \\
vocational training & $70.4 \%$ & $53.0 \%$ & $62.9 \%$ & $78.0 \%$ & $76.0 \%$ \\
college & $6.5 \%$ & $2.9 \%$ & $4.6 \%$ & $5.5 \%$ & $5.2 \%$ \\
\hline
\end{tabular}

Notes: Demographic characteristics of workers who transit to unemployment from out of the labor force (entrants from $N$ ) or all other states (other $U$ ) in January 2004 and 2005. The column for the entrants from $\mathrm{N}$ labeled corr. applies the inflow correction. See text for details. Row female shows the share of females in inflows, row age shows average age, and the bottom three rows show the shares of workers with at most high school education, vocational training, and a college education.

across the two years. In January 2004, new entrants are slightly younger, substantially more female (61\% vs. $43 \%$ ) and less educated (44\% vs. $23 \%$ with high school or less). When looking at all other entrants into unemployment (columns other $U$ ), we find that worker characteristics do not differ notably across these worker characteristics in January 2004 and 2005. Our inflow correction excludes entrants into the unemployment pool in early 2005 who are very detached from the labor market and are likely to have registered as unemployed solely due to the new registration requirements in 2005. Comparing the composition of the inflows in Table 1 suggests that a large group of entrants from out of the labor force in January 2005 falls into this category. The third column in entrants from $N$ reports worker characteristics for entrants after the inflow correction. We find that now worker characteristics of entrants in 2005 resemble much more closely those of the entrants in 2004, although some differences still remain. We refer to the sample after excluding these persons as the inflow-corrected sample. We will use the inflow-corrected sample as our benchmark sample for the rest of the paper.

Figure 1(b) shows the unemployment rate of the inflow-corrected sample (red solid line) and the full sample (blue dashed line). The spike in January 2005 disappears almost completely in the inflow-corrected sample. The persistently lower level of the inflow-corrected sample shows that the inflow of formerly nonemployed persons into the unemployment

are not unemployment spells. 
pool in early 2005 changed the composition toward persons who are less attached to the labor market. Given that we remove these workers completely from the sample, we also change unemployment rates before 2005, but this change is small. In 2014, unemployment rates in the inflow-corrected sample are about 0.75 percentage points lower. Looking at relative changes, we find that the inflow correction reduces the decrease in unemployment rates from roughly $40 \%$ to $30 \%$. Still, unemployment rates declined between 2005 and 2014 by more than $30 \%$. We provide a sensitivity analysis for skipping the inflow correction in Appendix C.1.

\subsection{Empirical results}

We consider the time period from 2003 to 2005 as the period of the reforms and use the years from to 1993 to 2002 to represent the labor market before the reform and use the years from 2008 to 2014 to represent the situation after the reform and an associated transition period. The sample period includes three recessions and in particular the financial crisis of 2008. One challenge is to disentangle the relative importance of structural changes in the labor market and changes from business cycle fluctuations when comparing the pre- and post-reform periods. We will rely on the structural model and provide in Section 4.2 a decomposition that disentangles structural changes and business cycle effects on worker flows and unemployment rates. We also provide an extensive sensitivity analysis to our empirical results that we summarize at the end of this section. We relegate details to Appendix C.

\subsubsection{Changes in separation and job finding rates}

Figure 2(a) shows the relative change in the separation rate for the period from 1993 to 2014. The separation rate is indexed to its average pre-reform level (1993-2002). This level is low in the German labor market over the entire time period. About $0.5 \%$ of workers transit from their employer to unemployment each month (see Table 2). Looking at the relative changes, we find a substantial $28 \%$ decline in separation rates between the pre-reform average and the separation rate in the post-reform period. When we consider the post-reform average including the Great Recession, the decline is smaller but still at $22 \%$.

Figure 2(b) shows the relative change in the job finding rate over time again indexed to its average pre-reform level. Job finding rates are typically slightly above $5 \%$ before the reform period and increase to slightly below $6 \%$ after the reform. In relative terms, the increase until 2014 constitutes a $13 \%$ increase in the job finding rate. If we include the Great Recession in the post-reform average, the increase amounts to only $10 \%$. Compared 
to the $28 \%$ decline in the separation rates, this suggests already that declining separation rates were the main driver behind the decline in unemployment rates over the decade following the Hartz reforms. The relative differences in changes remain largely unaffected when we include the Great Recession. The decline in separation rates is twice as large as the increase in the job finding rates.

Figure 2: Separation and job finding rates (1993 - 2014)

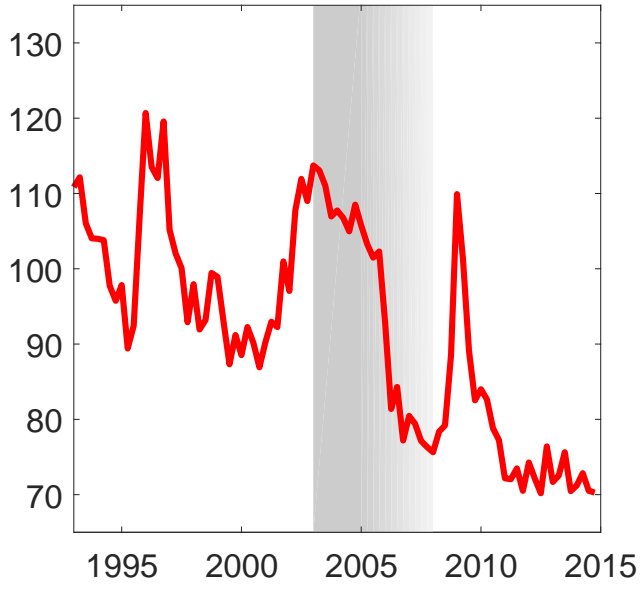

(a) Separation rate (indexed)

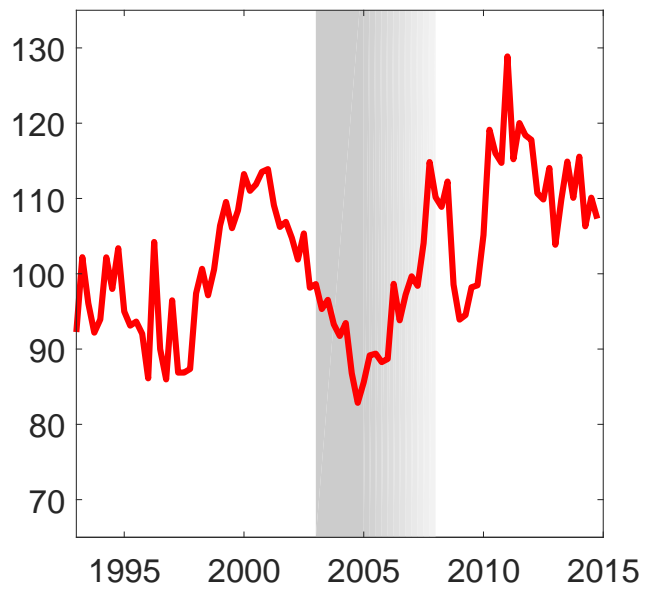

(b) Job finding rate (indexed)

Notes: Separation and job finding rates for West Germany 1993-2014. Both series have been indexed to their pre-reform level (1993-2002). The grey area marks the period 2003 to 2005 when the Hartz reforms were enacted. The fading out indicates the first transition years 2006 to 2008 after the reforms. Data are quarterly averages of monthly rates.

Table 2 uses a steady-state decomposition from a two-state stock-flow model to quantify the relative contribution of separation rates and job finding rates in explaining the $32 \%$ decline in unemployment rates until 2014. ${ }^{11}$ We consider the period from 1993 to 2002 as the pre-reform steady state and the period from 2011 to 2014 as the post-reform steady state to abstract from transition dynamics and the Great Recession as two exceptional periods. The last column of Table 2 reports the relative contributions of changes in the separation rate and the job finding rate to the unemployment rate. According to this decomposition, the declining separation rate accounts for $76 \%$ of the decline in the unemployment rate. The small residual of $4 \%$ relative to the empirically observed changes demonstrates that the simple two-state stock-flow model captures well the changes in the unemployment rate over time. Including the Great Recession in the decomposition leads to the same quantitative findings for the relative importance of separation and job finding rates for the decline in unemployment (see columns labeled 2008-2014).

\footnotetext{
${ }^{11}$ We use a two-state model so that the steady-state unemployment rate is $\bar{u}=\frac{\bar{\pi}_{e u}}{\bar{\pi}_{e u}+\bar{\pi}_{u e}}$ where $\bar{\pi}_{e u}$ denotes the steady-state separation rate (unemployment inflow) and $\bar{\pi}_{u e}$ denotes the steady-state job finding rate (unemployment outflow).
} 
Table 2: Before- and after-reform unemployment rates, transition rates, and steady-state decomposition

\begin{tabular}{lccccccc}
\hline & & & & $2008-2014$ & \multicolumn{2}{c}{$2011-2014$} \\
\cline { 5 - 8 } & $1993-2002$ & $2008-2014$ & $2011-2014$ & $\Delta$ & $\frac{\Delta \pi}{\Delta \bar{u}}$ & $\Delta$ & $\frac{\Delta \pi}{\Delta \bar{u}}$ \\
\cline { 2 - 8 } & & & & & & & \\
unemployment rate & $10.5 \%$ & $7.6 \%$ & $7.2 \%$ & $-27.5 \%$ & & $-31.5 \%$ & \\
separation rate & $0.6 \%$ & $0.5 \%$ & $0.5 \%$ & $-22.0 \%$ & $74.9 \%$ & $-27.7 \%$ & $75.8 \%$ \\
job finding rate & $5.2 \%$ & $5.7 \%$ & $5.9 \%$ & $10.1 \%$ & $30.8 \%$ & $13.3 \%$ & $31.6 \%$ \\
\hline
\end{tabular}

Notes: Columns 2-4 show the level of the unemployment rate, separation rate, and job finding rate before the Hartz reforms (1993 - 2002), after the Hartz reforms including the Great Recession (2008-2014), and after the Hartz reforms excluding the Great Recession (2011-2014). Columns labeled $\Delta$ report the percentage change in rates from before to after the reforms. Columns labeled $\frac{\Delta \pi}{\Delta u_{s s}}$ show the relative contribution to changes in steady-state unemployment rates from changes in separation and job finding rates. $\Delta \bar{u}$ indicates the change in the steadystate unemployment rate from before to after the Hartz reforms based on average rates before and after the reform.

Existing studies that explore the effect of UI reforms on the labor market focus on the effects on the job finding rate, either from changes in search effort or changes in contact rates for unemployed workers from more vacancy postings. The large contribution of changes in the separation rate to changes in the unemployment rate over time shows that such explanations fall short of explaining the data.

\subsection{Heterogeneity of changes in separation rates}

The last section documented that the decline in separation rates was the main driver of the reduction in unemployment rates in Germany after 2005. The decline of average rates hides a lot of heterogeneity that is informative about the underlying causal mechanism. Figure 3 shows unemployment benefit eligibility by employment duration and age before and after the reform. This benefit duration determines when workers lose eligibility for UI benefits and transit to unemployment assistance benefits before and benefits at subsistence level after the reform as unemployment assistance benefits were abolished by the Hartz reforms. If this abolition of the unemployment assistance benefits is the driver of the observed changes in separation rates, we should see heterogeneity in the changes of separation rates by employment duration and age. Looking at the pre-reform situation in Figure 3(a), we see that for workers younger than 45 the maximum benefit duration was 12 months. For older workers, we find a steep gradient in employment duration from 14 months after 30 months of previous employment to up to 30 months after five 
years of previous employment. Comparing this pattern to the post-reform regulation in Figure 3(b), we see that there is much less variation and that especially older, long-term employed workers see a strong decline in their benefit duration. For example, a 49-yearold worker with four years of previous employment receives, after the reform, UI benefits for 12 months, while before the reform she received UI benefits for 22 months. Figure 3(c) shows the relative changes in UI benefit durations for the different groups from before to after the reform. We find the largest decline for workers with more than three years of previous employment duration between ages 45 and 55. By contrast, there have been no changes for short-term employed workers (less than 28 months) and workers younger than 45. If the Hartz reforms are causal for the decline in separation rates, we expect this heterogeneity in the changes in the duration of benefit eligibility to be mirrored in the changes in separation rates.

A further dimension where we should see differences in separation rate changes, if the causal mechanism is related to the abolition of the long-term benefits, is wages because unemployment assistance was tied to a worker's last wage. A decoupling of long-term benefits from previous wages disproportionately affects workers with high wages because, after the reform, these workers face benefits at a subsistence level, independent of the previous wage, once UI benefits have expired.

We explore the changes in the separation rates along these dimensions of heterogeneity. In line with a causal mechanism that works through the cut in long-term wage-dependent benefits, we find that long-term employed and high-wage workers show stronger declines in separation rates compared to short-term employed and low-wage workers.

\subsubsection{Employment duration}

For the analysis of heterogeneity among workers with different employment duration, we split employed workers into two groups. The first group is short-term employed workers with at most three years of employment duration, and the second group is long-term employed workers with more than three years of employment duration. Table 3 shows the corresponding average levels for the pre- and post-reform period. Looking at the levels, we see that short-term employed workers have separation rates that are more than five times higher than those of the long-term employed workers in the period 1993 to 2002 (1.37\% vs $0.26 \%)$. This difference further increases in the period 2008 to 2014 (1.15\% vs $0.18 \%$ ). After 2008, separation rates differ by more than a factor of six. The reason is the much stronger relative decline in the separation rate for long-term employed workers after 2008.

The stronger decline can be seen in Figure 4, which shows the time series of relative 
Figure 3: Changes in benefit duration by age and employment duration

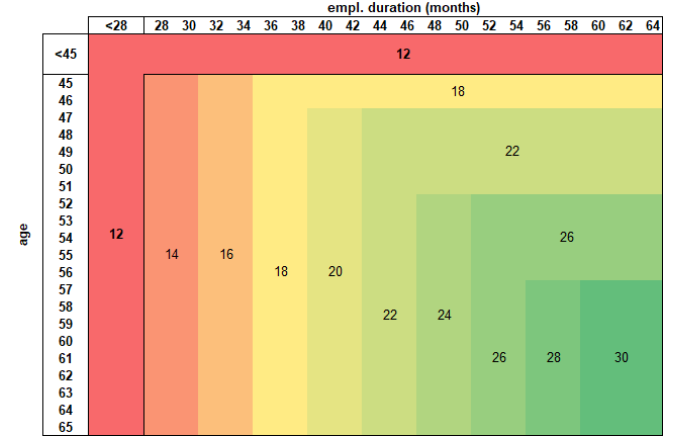

(a) Benefit duration pre-reform

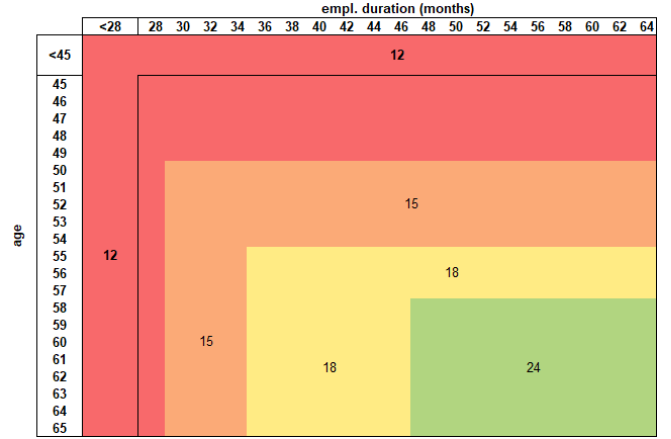

(b) Benefit duration post-reform

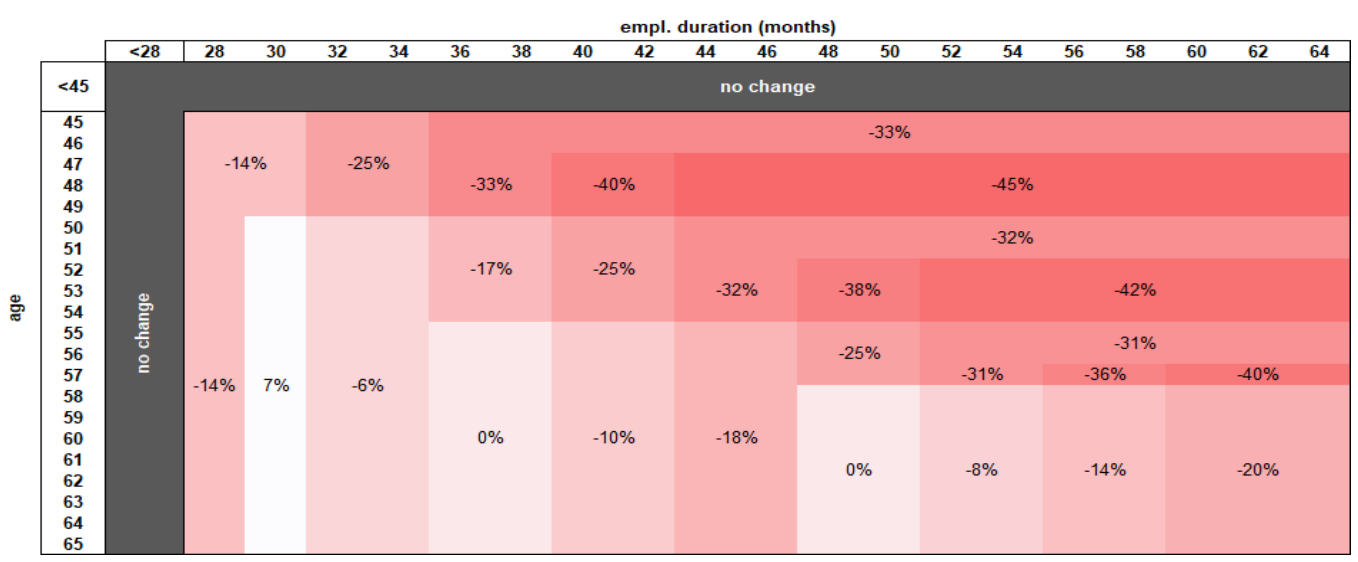

(c) Change in benefit duration

Notes: Maximum eligibility duration for short-term unemployment benefits in months by age and employment duration. Employment duration refers to a reference period of 5-7 years prior to the unemployment spell. Panel (a) shows maximum durations before the reform. Panel (b) shows the maximum durations after the reform in 2008, i.e. after all grandfathering rules had expired. Panel (c) shows the relative change in maximum durations in percent for each combination of age and employment duration.

changes in separation rates for different groups of short-term and long-term employed workers. Looking at Figure 4(a), we find a strong divergence in the time series of separation rates between short-term and long-term employed workers after the Hartz reforms. The strong divergence persists so that, after the reform, separation rates of long-term employed workers have declined twice as much as those for short-term employed workers.

\subsubsection{Age}

In addition to employment duration, age determines the duration of benefit eligibility in the UI system (Figure 3). We therefore dissect the data in Figures 4(b) and 4(c) further by looking at young and old workers by employment duration. Looking at younger workers in Figures 4(b), we find, in line with the changes in eligibility duration, no 
Table 3: Change in separation rates by employment duration and age

\begin{tabular}{lccc}
\hline & $1993-2002$ & $2008-2014$ & $\Delta \%$ \\
\hline all & $0.63 \%$ & $0.49 \%$ & $-22.0 \%$ \\
emp. duration $\leq 3$ years & $1.37 \%$ & $1.15 \%$ & $-16.2 \%$ \\
emp. duration $>3$ years & $0.26 \%$ & $0.18 \%$ & $-33.3 \%$ \\
\hline
\end{tabular}

Notes: Monthly separation rates before and after the Hartz reforms by employment duration and age. Column $\Delta$ reports the percentage change in rates from the period before the Hartz reforms to the period after the Hartz reforms.

differential changes between short-term and long-term employed workers. Separation rates decline in lockstep for these two groups. By contrast, but in close alignment with the changes in eligibility duration, we find that long-term employed, older workers show the strongest reduction in separation rates, while older short-term employed workers show a reduction that is only half as large (Figure 4(c)). Looking at short-term employed workers across age groups provides a further sanity check for heterogeneous changes in separation rates because there have been no differential changes in benefit eligibility duration for short-term employed workers. In line with no such heterogeneity, we find a strikingly close tracking of separation rate changes for short-term employed young (age 15-44) and old workers (age 45-64) in Figure 4(d). For both age groups separation rates decline in lockstep following the Hartz reforms. These results by age further strengthen our finding that separation rates decline more for workers who have been more adversely affected by the cut in benefit eligibility from the Hartz reforms. Therefore, this additional heterogeneity in changes in separation rates provides further support for a causal link from the UI reform to the observed changes in labor market dynamics.

In Appendix C.3, we provide a more detailed analysis of changes by age groups. One finding from this analysis is that workers closer to retirement show an even stronger decline in separation rates. Their decline in separation rates follows a longer-run trend that accelerated during the 2000s so that, over time, unemployment rates for older workers decreased more than those for younger workers. This trend was accompanied by a strongly rising labor force participation rate of workers close to retirement age. We abstract from this fact of independent interest as it is beyond the scope of this paper. ${ }^{12}$ In our

\footnotetext{
${ }^{12}$ Jäger et al. (2018) provide a detailed investigation of this topic. They study changes in separation rates of male workers towards the end of working life ( 50 years and older) in Austria after changes in UI benefit durations. They exploit staggered changes in UI eligibility similar to those shown in Figure 3 in combination with regional variation. Jäger et al. rely on a microeconometric analysis to characterize
} 
Figure 4: Separation rates by age and employment duration (1993 - 2014)

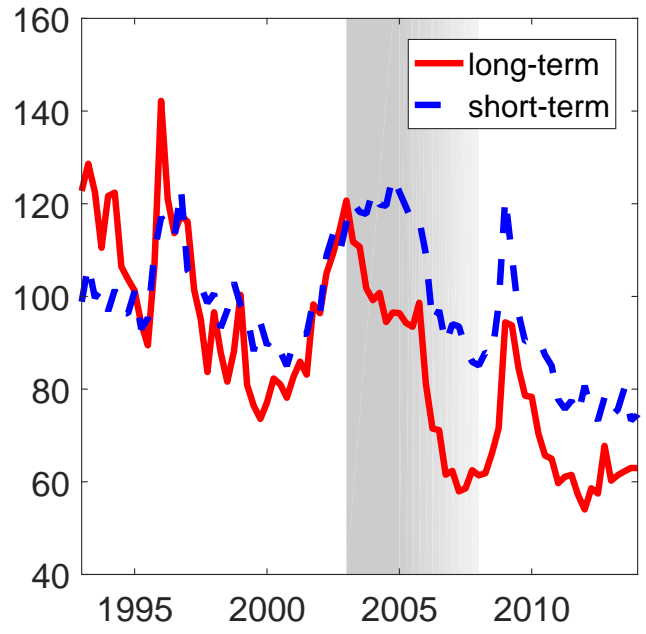

(a) all workers

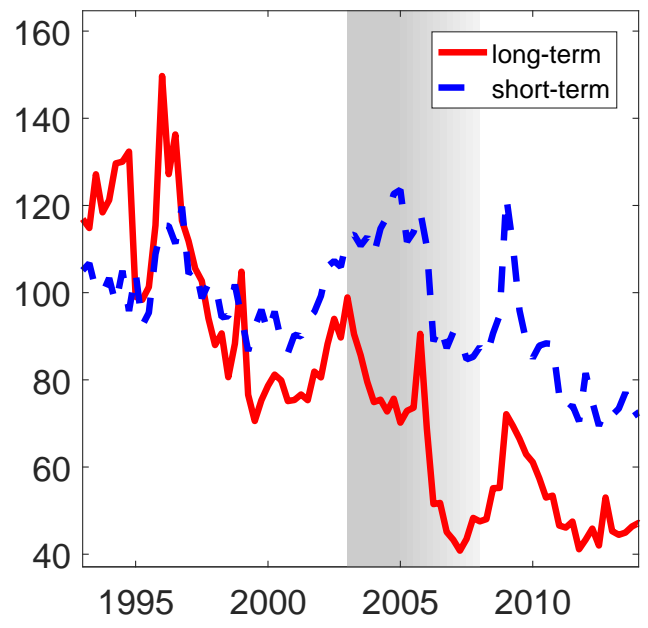

(c) age $45-64$

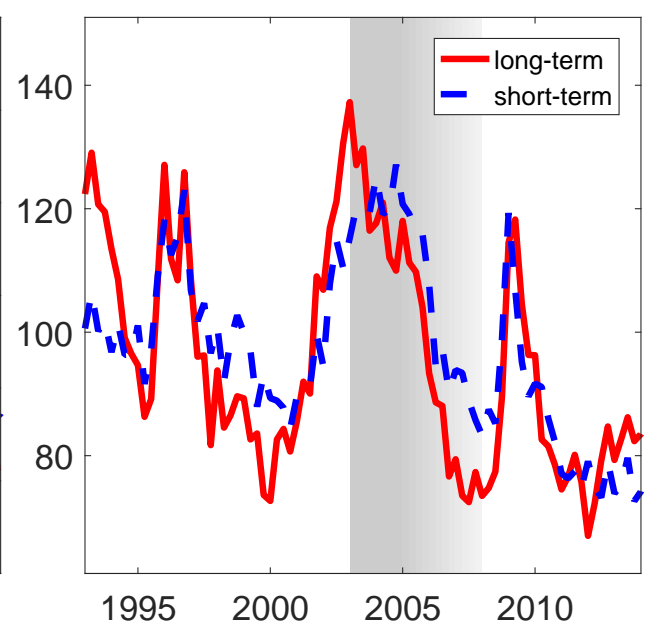

(b) age $15-44$

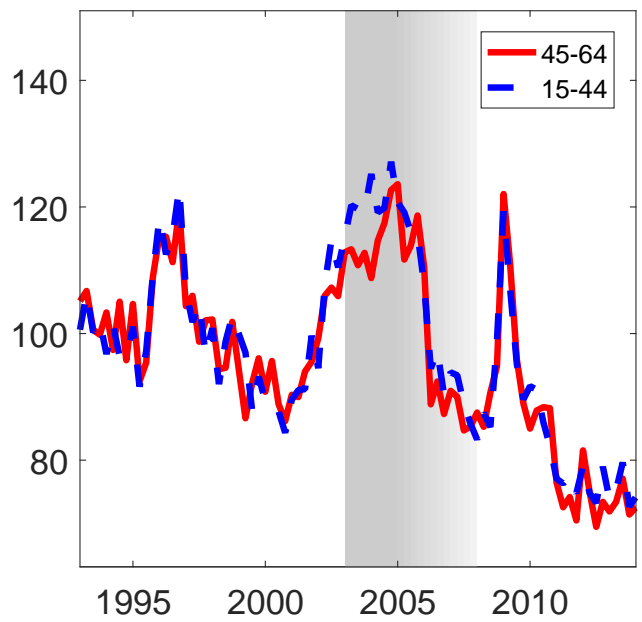

(d) short-term employed

Notes: Separation rates by employment duration and age for West Germany 1993 - 2014, indexed to their pre-reform level (1993-2002). The red solid lines in panels (a)-(c) mark the separation rate for long-term employed workers who were continuously employed for three years or more. The blue dashed lines in panels (a)-(c) mark the separation rate for short-term employed workers with at most three years of continuous employment. Panel (d) shows the separation rate for short-term employed workers separately for young (age 15-44, blue dashed line) and old employees (age 45-64, red solid line). The grey area indicates the period of the implementation of the Hartz reforms. The grey area marks the period 2003 to 2005 when the Hartz reforms were enacted. The fading out indicates the first transition years 2006 to 2008 after the reforms. Data are quarterly averages of monthly rates.

theoretical analysis, we will abstract from the additional age heterogeneity to keep the model parsimonious and because most of the heterogeneity in the changes in separation

marginal jobs separating after changes in workers' outside options. In line with our empirical results, they document large changes in separation rates after changes in potential benefit duration. 
rates is captured by differences in employment duration.

\subsubsection{Wages}

Figure 5 shows the relative changes in separation rates from before to after the UI reform along the wage distribution. In a first step, we consider two groups of workers: low-wage workers in the bottom three deciles of the wage distribution and high-wage workers in the fourth to seventh deciles. In a second step, we provide more granular changes showing that the differences further up in the wage distribution are, if anything, larger. Figure 5 (a) compares changes in separation rates for low-wage workers and high-wage workers over time. Separation rates before 2005 comove closely and start to diverge thereafter. By 2014, high-wage workers saw their separation rates decline by almost twice as much as those for low-wage workers. Figure 5(b) dissects the wage distribution finer. It quantifies for each wage decile by how much the average separation rate decreased from the decade before the reform (1993-2002) to the post-reform period (2008-2014). Evidently, the higher wage deciles experienced the largest declines in separation rates. Separation rates hardly change at the bottom of the wage distribution, decline by between $20 \%$ to $30 \%$ in the middle, and plummet by almost $50 \%$ at the top. The stronger decline in separation rates for high-wage workers further supports a causal link from the UI reform to the observed changes in labor market dynamics because the reform replaced long-term wagedependent benefits by subsistence benefits independent of previous wages. This change affected in particular high-wage workers.

The results on employment duration, age, and wage heterogeneity all show a larger drop in separation rates for groups that have been more adversely affected by the Hartz reforms (Figure 3). We speak to the observed heterogeneity in our quantitative model below. In the model, the removal of long-term wage-dependent benefits will lead to heterogeneous reactions in separation rates, and high-wage, long-term employed workers will see a stronger reduction in their separation rates in line with the empirical evidence from this section.

\subsection{Sensitivity and comparison to other data sources}

In the first step, we discuss evidence from other independent data sources to further support our empirical evidence on the dominant role of falling separation rates in explaining the decline in German unemployment rates after 2005. The first additional data source is the reports of the employment agency on monthly unemployment benefit claims. In a previous study (Hartung et al. (2016)), we construct a historical series on worker flows for the period 1967 to 2014 based on these data and demonstrate that, during the pe- 
Figure 5: Changes in separation rates by wages

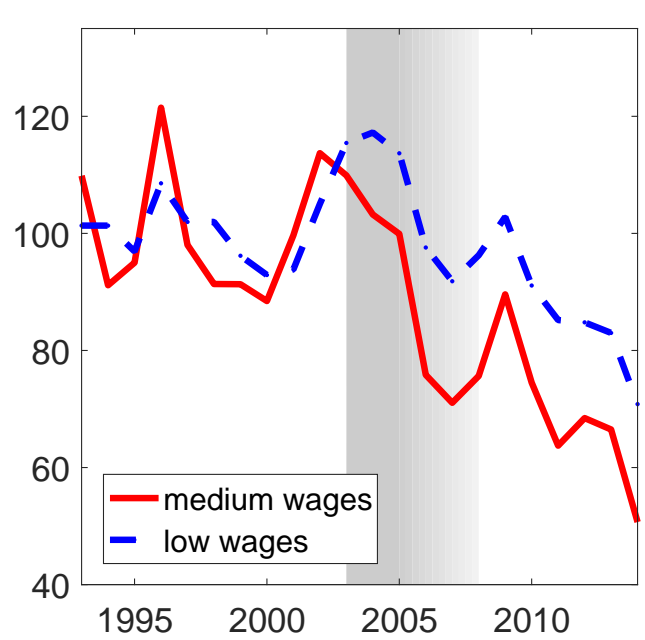

(a) Separation rate by wage bracket

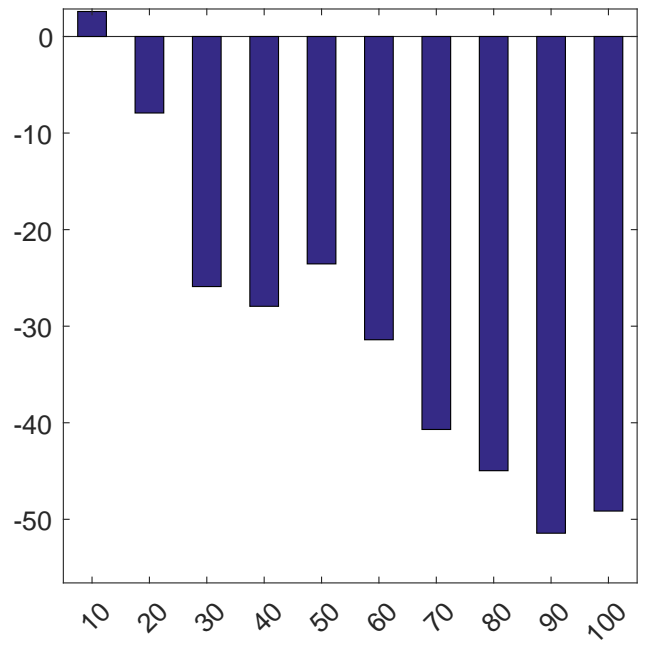

(b) Relative change post-reform (in \%)

Notes: Left panel shows changes in separation rates for high and low wage groups of workers in West Germany 1993-2014. The red solid line shows workers with wages between $40 \%$ and $70 \%$ of the wage distribution. The blue dashed line shows workers with wages up to $30 \%$ of the wage distribution. The grey area marks the period 2003 to 2005 when the Hartz reforms were enacted. The fading out indicates the first transition years 2006 to 2008 after the reforms. Data are pooled at the annual level. Right panel shows relative declines of average separation rates for the entire wage distribution from before the reform (1993-2002) to after the reform (2008-2014) in \%. Deciles of the wage distribution are shown on the horizontal axis.

riod of overlap, it closely matches worker flows from the SIAB microdata. We explain in Hartung et al. (2016) how this data series can be constructed in real time from publicly available data sources. The second data source is flow rates in and out of unemployment that have been reported by the German employment office since 2006. These flow rates are based on registered cases of workers transiting from employment into unemployment and vice versa. These rates are based on case counts rather than worker counts. To be consistent with our structural model, we use worker counts based on reference weeks for our empirical analysis. This difference in measurement will lead to differences in the level of rates because multiple cases can occur for one worker within one month. This is the well-known time aggregation problem, as discussed, for example, in Shimer (2012).

Figure 6 shows three alternative measures for the separation rate and the job finding rate. The first one is our benchmark measure constructed from the SIAB microdata (red solid line); the second one is constructed by the German employment office (blue dashed line), the so-called inflow hazard rate (Zugangsrisiko) and departure rate (Abgangschance); and the third one is the measure constructed from UI benefit claims in Hartung et al. (2016) (black dotted line). We find that the two additional measures strongly support our finding 
Figure 6: Alternative measures for transition rates

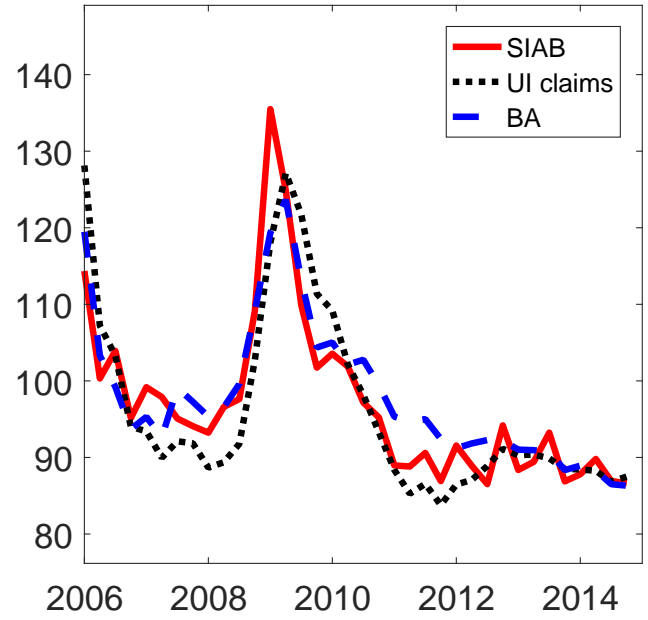

(a) Separation rates

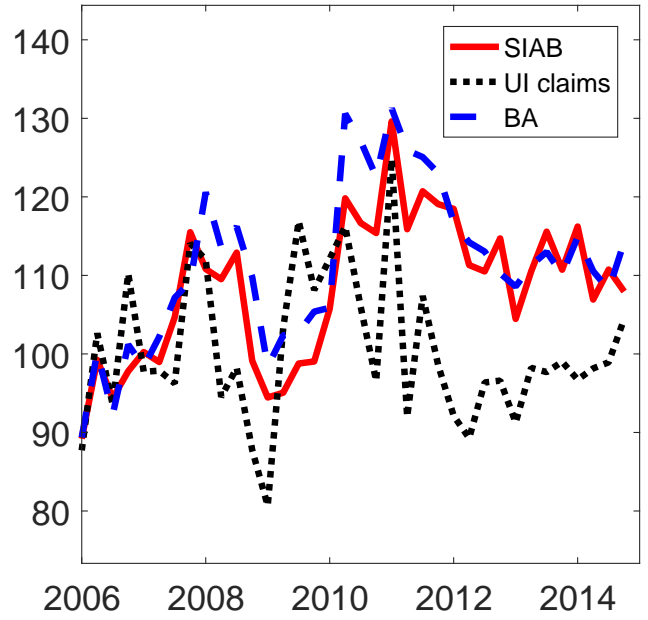

(b) Job finding rates

Notes: The figures show separation and job finding rates for the benchmark sample from the SIAB microdata (red solid line). The blue dashed line shows flow rates reported by the German employment office. The black dotted line shows flow rates constructed in Hartung et al. (2016) based on new unemployment benefit claims. All rates are indexed to the level in the first two years displayed in the graphs (2006-2007). See text for further details.

of decreasing separation rates as the macroeconomic driver of falling unemployment.

Next, we also summarize the findings from our sensitivity analysis. We relegate details to Appendix C. In a first step of our sensitivity analysis, we demonstrate that skipping the inflow correction mainly leads to lower job finding rates after the reform due to the larger unemployment pool (see C.1). In a second step, we control for changes in the composition of the employed in terms of worker characteristics using a linear regression model. Fixing the composition of the employed at the level in 2000, we find that compositional changes alone are negligible for explaining changes in separation rates over time (see C.2). In a third step, we provide results for East Germany (see C.4), counting marginally employed workers who are registered as unemployed as employed (see C.5), and counting workers in active labor market programs among the employed (see C.6). ${ }^{13}$ We find the documented results to be robust.

\section{Model}

This section applies economic theory to causally link the changes in the unemployment insurance system to the observed changes in labor market dynamics and unemployment

\footnotetext{
${ }^{13}$ After the reform, workers who participate in active labor market programs were no longer counted as unemployed.
} 
rates. We develop a labor market search and matching model with aggregate fluctuations, endogenous separations, and worker heterogeneity. In the model, time is discrete and there is a continuum of workers of measure one and a positive measure of firms. Workers and firms are risk neutral and discount the future at rate $\tilde{\beta}$. Each period there is a positive probability that a worker leaves the labor force for good. We denote this probability by $\omega$ and the product of the time discount factor and the probability of remaining in the labor market by $\beta=\tilde{\beta}(1-\omega)$. A worker who leaves the labor force is immediately replaced by a newborn worker so that there is always a constant mass of workers. Workers in the model are either employed or unemployed. We consider single-worker firms and refer to a worker-firm pair as a match.

Employed workers have one of two skill levels $x_{1}$ or $x_{2}$ with $x_{1}<x_{2}$. We refer to workers with skill level $x_{1}$ as low skill and workers with skill level $x_{2}$ as high skill. Workers who enter the labor force start as low skill. While working, workers accumulate skills by learning-by-doing. An employed low-skill worker stochastically gains skills at rate $\alpha$. The accumulated skills are lost upon separation. Employed workers become eligible for unemployment benefits with employment duration. Since the accumulation of skills and benefit eligibility both depend on employment duration, we economize on the state space and assume that eligibility and skill level are perfectly correlated so that all high-skill workers are eligible for unemployment benefits. ${ }^{14,15}$ As discussed below, low-skill workers are eligible for social assistance benefits or unemployment benefits if they separate and enter into unemployment. We denote the share of employed workers in the population in state $x_{1}$ by $e_{1}$ and the share of employed workers in state $x_{2}$ by $e_{2}$. Denoting the current period's state by $x$ and the next period's state by $x^{\prime}$, the law of motion for $x$ conditional on staying employed is

$$
x^{\prime}=x_{2} \quad \text { if } x=x_{2}
$$

and if $x=x_{1}$, the law of motion is

$$
x^{\prime}= \begin{cases}x_{2} & \text { with probability } \alpha \\ x_{1} & \text { with probability } 1-\alpha\end{cases}
$$

We denote the state of unemployed workers by $b$ and the state can take three values $b_{j}$

\footnotetext{
${ }^{14}$ We abstract from age heterogeneity that would lead to the introduction of an additional state variable but the underlying economic mechanism would be identical to the mechanism that works along the employment duration dimension. Krause and Uhlig (2012) follow the same modelling approach.

${ }^{15}$ In general, experience and skill accumulation need not be perfectly correlated. The empirical evidence on wage growth for the German labor market finds strong returns to experience in the first two years (Dustmann and Meghir (2005)). This suggests that productivity gains and eligibility in the data are also highly correlated so that we are confident that our assumption to economize on the state space is of minor importance.
} 
with $j=1,2,3$. The different states describe the current eligibility level of the unemployed: social assistance $\left(b_{1}\right)$, unemployment assistance $\left(b_{2}\right)$, and unemployment benefits $\left(b_{3}\right)$. It holds that $b_{1} \leq b_{2}<b_{3}$. Upon entering unemployment, high-skill workers are eligible for unemployment benefits $b_{3}$. When entering unemployment, low-skill workers enter in state $b_{3}$ with probability $\gamma$, and with probability $1-\gamma$, they enter unemployment in state $b_{1}$. Stochastic eligibility for low-skill workers captures in a parsimonious way the more complex eligibility rules in the actual system. ${ }^{16}$ During unemployment, the eligibility state stochastically changes over time. Workers in state $b_{3}$, receiving unemployment benefits, transit to state $b_{2}$, receiving unemployment assistance, with probability $\delta_{3}$. Workers who are in state $b_{2}$ transit to state $b_{1}$, receiving social assistance, with probability $\delta_{2}$. We denote the mass of workers in each state by $u_{j}$ for $j=1,2,3$. Denoting the current period's state by $b$ and the next period's state by $b^{\prime}$, the law of motion for $b$ conditional on staying unemployed is

$$
b^{\prime}=b_{1} \quad \text { if } b=b_{1}
$$

and if $b=b_{j}$ for $j=2,3$, the law of motion is

$$
b^{\prime}=\left\{\begin{array}{cl}
b_{j} & \text { with probability } 1-\delta_{j} \\
b_{j-1} & \text { with probability } \delta_{j}
\end{array}\right.
$$

When unemployed workers re-enter employment, they enter with state $x_{1}$. The law of motion for the worker state at the transition from unemployment to employment is hence $x^{\prime}=x_{1}$ independent of $b$. When transiting from employment into unemployment, the law of motion is

$$
b^{\prime}=b_{3} \quad \text { if } x=x_{2}
$$

and if $x=x_{1}$, the law of motion is

$$
b^{\prime}= \begin{cases}b_{3} & \text { with probability } \gamma \\ b_{1} & \text { with probability } 1-\gamma\end{cases}
$$

Each period consists of two stages. The first stage is the separation stage when each match decides about separating into unemployment or entering the production stage. The second stage is the production stage for the employed and the search stage for the

\footnotetext{
${ }^{16}$ There are two main reasons for the misalignment of employment duration and eligibility: First, employees with more than one year of employment duration are already eligible for UI benefits for a period of 6 months, which then gradually increases to 12 months the longer a person has been working. Second, employment duration in the legislation does not refer to the latest continuous employment spell but the accumulated duration in a reference period that varied between 2 and 7 years.
} 
unemployed. Search happens simultaneously with production. We refer to this stage, respectively, as the search or production stage depending on whether the unemployed or the employed are considered. We abstract from on-the-job search. Labor market exit happens with probability $\omega$ at the end of the period. A match that does not separate enters the production stage and produces $y=\exp (a+x)$ units of output depending on skill level $x$ and the aggregate productivity state $a$. The aggregate productivity state $a$ follows an $\operatorname{AR}(1)$ process with autocorrelation $\rho$ and variance $\sigma_{a}^{2}$.

The aggregate state of the economy $s$ comprises the aggregate productivity state $a$ and the distribution of workers over states $s=\left\{a, e_{1}, e_{2}, u_{1}, u_{2}\right\}$ where we dropped $u_{3}$ due to the identity $e_{1}+e_{2}+u_{1}+u_{2}+u_{3}=1$. The state of a match at the beginning of the period is described by the tuple $(x, s)$ of the idiosyncratic state $x$ and the aggregate state $s$. The state of an unemployed worker is $(b, s)$, where the idiosyncratic state is the current benefit eligibility.

At the separation stage, each match draws an idiosyncratic cost shock $\varepsilon$ and then, depending on the state of the match $(x, s)$, decides whether to enter the production stage. For analytical tractability, we assume that the shock $\varepsilon$ is independently and identically distributed across matches and time and is drawn from a logistic distribution $F$ with mean $\bar{\varepsilon}$ and variance $\sigma_{\varepsilon}^{2}=\pi^{2} \frac{\psi_{\varepsilon}^{2}}{3}$. A match that decides to separate does not pay these costs. Optimal behavior follows a threshold rule where separations happen when the idiosyncratic cost shock $\varepsilon$ is larger than a state-specific threshold $\varepsilon^{u}(x, s)$. This threshold is determined as part of the bargaining process between the worker and the firm so that separation decisions will be individually efficient. The average separation rate of a match with state $(x, s)$ is $\pi_{e u}(x, s)=\operatorname{Prob}\left(\varepsilon \geq \varepsilon^{u}(x, s)\right)$. Workers who separate at the separation stage enter unemployment in the current period, receive benefits, and start searching during the search stage of the current period. Aggregate output in a period is $y=\sum_{i} e_{i}\left(1-\pi_{e u}\left(x_{i}, s\right)\right) \exp \left(a+x_{i}\right)$, where $e_{i}\left(1-\pi_{e u}\left(x_{i}, s\right)\right)$ is the mass of employed workers of type $i$ who produce at the production stage. ${ }^{17}$

We denote the value of a firm matched to a worker of skill type $x$ before the realization of the idiosyncratic shock $\varepsilon$ by $J(x, s)$. The value $J(x, s)$ expressed recursively is

$$
J(x, s)=\int_{-\infty}^{\varepsilon^{u}(x, s)}\left(\exp (a+x)-\varepsilon-w(x, s)+\beta \mathbb{E}\left[J\left(x^{\prime}, s^{\prime}\right) \mid x, s\right] d F(\varepsilon)\right)
$$

where $w(x, s)$ denotes the wage for the worker and expectations are taken over the realiza-

\footnotetext{
${ }^{17}$ The share $e_{i}$ is at the beginning of the period before the separation stage. Of all employed workers in state $(x, s)$, only a fraction $1-\pi_{e u}(x, s)$ will not separate and produce at the production stage.
} 
tion of the idiosyncratic and aggregate state next period $\left(x^{\prime}, s^{\prime}\right)$ conditional on the current state $(x, s)$. The upper integration bound is the threshold value $\varepsilon^{u}(x, s)$ that determines separation. We assume that the continuation value of the firm after separation is zero. Below, we explain how $\varepsilon^{u}(x, s)$ and $w(x, a)$ are determined. We exploit the properties of the logistic distribution to get a closed form for the integral of the idiosyncratic shocks $\varepsilon$ that we denote by $\Psi_{\varepsilon}\left(\pi_{e u}\right)$

$$
\Psi_{\varepsilon}\left(\pi_{e u}\right)=\int_{-\infty}^{\varepsilon^{u}}-\varepsilon d F(\varepsilon)=-\left(1-\pi_{e u}\right) \bar{\varepsilon}-\psi_{\varepsilon}\left(\left(1-\pi_{e u}\right) \log \left(1-\pi_{e u}\right)+\pi_{e u} \log \left(\pi_{e u}\right)\right)
$$

with $\pi_{e u}=1-F\left(\varepsilon^{u}\right)$ denoting the separation probability given the threshold value $\varepsilon^{u}$. The firm value simplifies to

$$
J(x, s)=\left(1-\pi_{e u}(x, s)\right)\left(\exp (a+x)-w(x, s)+\beta \mathbb{E}\left[J\left(x^{\prime}, s^{\prime}\right) \mid x, s\right]\right)+\Psi_{\varepsilon}\left(\pi_{e u}(x, s)\right)
$$

The state of an unemployed worker at the beginning of the period is $(b, s)$ with the idiosyncratic state $b$ describing the worker's current benefit level. The worker's flow utility in unemployment is $b+h$, where $h$ is the utility value of leisure relative to working (disutility of working is normalized to zero). Search is random so all workers receive job offers with the same probability $\lambda(s)$ that only depends on the aggregate state of the economy. We assume that each job offer is associated with an idiosyncratic stochastic utility component $\nu$ capturing the personal valuation of workers for jobs. This stochastic non-pecuniary job component comprises, among other things, commuting time, workplace atmosphere, and working schedules of the offered job. It captures in a parsimonious way endogenous search behavior of the unemployed. Unemployed workers optimally follow a reservation utility rule and accept all job offers with $\nu$ larger than a statedependent threshold $\nu^{u}(b, s)$. We assume $\nu$ is independently and identically distributed and is drawn from a logistic distribution $G$ with state-specific mean $\bar{\nu}(b)$ and variance $\sigma_{\nu}^{2}=\pi \frac{\psi_{\nu}^{2}}{3}$. The average acceptance probability of an unemployed worker in state $(b, s)$ is $q(b, s)=1-G\left(\nu^{u}(b, s)\right)$ and the transition rate into employment is $\pi_{u e}(b, s)=\lambda(s) q(b, s)$ combining contact rate $\lambda(s)$ and acceptance rate $q(b, s)$. The recursive formulation of the 
value of an unemployed worker in state $(b, s)$ is

$$
\begin{aligned}
V_{u}(b, s)= & b+h+\beta\left(\lambda(s) \int_{\nu^{u}(b, s)}^{\infty}\left(\mathbb{E}\left[V_{e}\left(x^{\prime}, s^{\prime}\right) \mid b, s\right]-\nu\right) d G(\nu)\right. \\
& \left.+\lambda(s) \int_{-\infty}^{\nu^{u}(b, s)} \mathbb{E}\left[V_{u}\left(b^{\prime}, s^{\prime}\right) \mid b, s\right] d G(\nu)+(1-\lambda(s)) \mathbb{E}\left[V_{u}\left(b^{\prime}, s^{\prime}\right) \mid b, s\right]\right) \\
= & b+h+\beta\left(\pi_{u e}(b, s) \mathbb{E}\left[V_{e}\left(x^{\prime}, s^{\prime}\right) \mid b, s\right]+\left(1-\pi_{u e}(b, s)\right) \mathbb{E}\left[V_{u}\left(b^{\prime}, s^{\prime}\right) \mid b, s\right]\right. \\
& \left.+\lambda(s) \Psi_{\nu}(q(b, s))\right)
\end{aligned}
$$

where $V_{e}(x, s)$ denotes the value of being employed in state $(x, s)$ and the last line exploits again the properties of the logistic distribution with $\Psi_{\nu}(q)=-q \bar{\nu}(b)-\psi_{\nu}((1-q) \log (1-$ $q)+q \log (q))$. The state-specific means $\bar{\nu}(b)$ allow us to obtain job finding rates that are falling with unemployment duration. Such changing utility shocks capture, for example, decreasing motivation to apply for jobs, more effort to prepare for job interviews, and to be up to date with job requirements.

An employed worker who does not separate at the separation stage receives her wage at the production stage. At the end of the production stage, the stochastic skill accumulation takes place. The recursive representation of the value function of employed workers is

$$
V_{e}(x, s)=\left(1-\pi_{e u}(x, s)\right)\left(w(x, s)+\beta \mathbb{E}\left[V_{e}\left(x^{\prime}, s^{\prime}\right) \mid x, s\right]\right)+\pi_{e u}(x, s) \mathbb{E}\left[V_{u}\left(b^{\prime}, s\right) \mid x\right] .
$$

Note that in the case of separation, expectations are only over the idiosyncratic benefit state $b$, and although the worker becomes unemployed in the current period, we denote the stochastic benefit level in an abuse of notation by $b^{\prime}$. The benefit level follows the laws of motion for $b$ in eq. (3) and (4).

A Cobb-Douglas matching function $m=\varkappa v^{1-\varrho} u^{\varrho}$ determines the number of matches $m$ between vacancies $v$ and unemployed workers $u=u_{1}+u_{2}+u_{3}$ during the search stage of each period. The contact rate from a worker's perspective is $\lambda=\frac{m}{u}=\varkappa \theta^{1-\varrho}$ and from a firm's perspective is $\lambda_{v}=\frac{m}{v}=\varkappa \theta^{-\varrho}$ with labor market tightness $\theta=\frac{v}{u}$. The number of vacancies at the search stage of each period is determined by a free-entry condition

$$
\kappa=\lambda_{v}(s) \beta \sum_{j=1}^{3} q\left(b_{j}, s\right) \frac{u_{j}}{u} \mathbb{E}\left[J\left(x^{\prime}, s^{\prime}\right) \mid b_{j}, s\right]
$$

where $\kappa$ denotes the per-period cost to post a vacancy. Firms posting vacancies take 
into account the acceptance rates $q\left(b_{j}, s\right)$ of workers with different unemployment benefit eligibility. Recall that all newly hired workers start with $x^{\prime}=x_{1}$ so there is only uncertainty regarding the aggregate state $s^{\prime}$ for the next period when posting a vacancy. Wages and threshold values for separation decisions $\varepsilon^{u}(x, s)$, equivalently separation probabilities $\pi_{e u}(x, s)$, are determined by a state-contingent Nash bargaining between the worker and firm over the joint surplus of the match $S(x, s)=J(x, s)+V_{e}(x, s)-$ $\mathbb{E}\left[V_{u}\left(b^{\prime}, s\right)\right] \equiv J(x, s)+\Delta(x, s)$ (see Pissarides (2000, Ch. 2)). We denote the bargaining power of the worker by $\mu$. The Nash-bargaining problem reads $\arg \max _{\left\{w, \varepsilon^{u}\right\}} J(x, s)^{1-\mu} \Delta(x, s)^{\mu}$. The first-order condition with respect to wages delivers the standard surplus sharing rule

$$
\mu J(x, s)=(1-\mu) \Delta(x, s) .
$$

The first-order condition with respect to the separation cut-off $\varepsilon^{u}$ characterizes the cut-off value in terms of the separation rate $\pi_{e u}=1-F\left(\varepsilon^{u}\right)$ as

$$
\pi_{e u}(x, s)=\left(1+\exp \left(\psi_{\varepsilon}^{-1}(\exp (a+x)-\bar{\varepsilon}+\tilde{S}(x, s))\right)\right)^{-1}
$$

with $\tilde{S}(x, s)=\beta \mathbb{E}\left[S\left(x^{\prime}, s^{\prime}\right) \mid x, s\right]+\beta \mathbb{E}\left[V_{u}\left(b^{\prime}, s^{\prime}\right) \mid x, s\right]-\mathbb{E}\left[V_{u}\left(b^{\prime}, s\right) \mid x\right]$ where $\mathbb{E}\left[V_{u}\left(b^{\prime}, s\right) \mid x\right]$ denotes the expected value from unemployment in the current period taking into account stochastic eligibility (see eq. (8)). We get that the optimal separation probability $\pi_{e u}(x, s)$ is decreasing in current output $\exp (a+x)$ net of mean costs $\bar{\varepsilon}$ and in an adjusted future match surplus $\tilde{S}(x, s)$ that takes into account the option value from skill accumulation on unemployment benefit eligibility $\beta \mathbb{E}\left[V_{u}\left(b^{\prime}, s^{\prime}\right) \mid x, s\right]-\mathbb{E}\left[V_{u}\left(b^{\prime}, s\right) \mid x\right]$.

\subsection{Calibration}

We calibrate the model to match the pre-reform labor market dynamics of the German labor market. We show all calibrated parameters in Table 4. For the calibration, we take a model period to be one month. We set a first group of parameters outside the model. The discount factor $\tilde{\beta}$ is set to match an annual interest rate of $4 \%$ so that $\tilde{\beta}=0.996$, and the parameter $\varrho$ of the matching function and the bargaining power of the worker $\mu$ are set to $\varrho=\mu=0.5$.

We describe below how we set the parameters of the unemployment insurance system using independent evidence. Remaining model parameters are set within the model by targeting data moments. Dynamics in the model are only driven by aggregate productivity shocks $a$. To simulate the model, we linearize the model around its deterministic steady state and use a Kalman filter on GDP growth per capita to determine the time 
Table 4: Calibrated parameters

\begin{tabular}{|c|c|c|c|}
\hline & Parameter & Value & Description \\
\hline \multirow{6}{*}{ 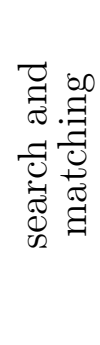 } & $\varrho$ & 0.5 & elasticity of the matching function \\
\hline & $\varkappa$ & 0.164 & efficiency of the matching function \\
\hline & $\kappa$ & 0.772 & vacancy posting costs \\
\hline & $\mu$ & 0.5 & worker's bargaining power \\
\hline & $\gamma$ & 0.52 & eligibility rate of low-skill workers \\
\hline & $\omega$ & 0.010 & labor market exit rate \\
\hline \multirow{6}{*}{ 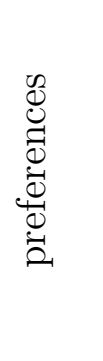 } & $\tilde{\beta}$ & 0.996 & time discount factor \\
\hline & $h$ & 0.266 & flow leisure utility \\
\hline & $\bar{\nu}\left(b_{1}\right)$ & 0.761 & \\
\hline & $\bar{\nu}\left(b_{2}\right)$ & 0.761 & means of non-pecuniary shocks \\
\hline & $\bar{\nu}\left(b_{3}\right)$ & -0.138 & \\
\hline & $\psi_{\nu}$ & 0.080 & dispersion of non-pecuniary shocks \\
\hline \multirow{4}{*}{ 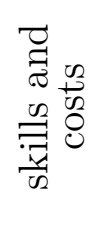 } & $\bar{\varepsilon}$ & 0.400 & mean of cost shocks \\
\hline & $\psi_{\varepsilon}$ & 0.633 & dispersion of cost shocks \\
\hline & $\alpha$ & 0.028 & probability of skill accumulation \\
\hline & $\Delta x$ & 0.041 & skill level difference $x_{2}-x_{1}$ \\
\hline
\end{tabular}

series of aggregate productivity shocks $a$ (see Jung and Kuhn (2014)). ${ }^{18}$ This approach builds on ideas from Murtin and Robin (2016). Within our calibration routine, we adjust model parameters until the simulated model moments match their data counterparts. We next provide intuitive identification arguments but abstain from a formal proof of identification.

Each match produces output with labor and a stochastic cost component, which we interpret as payments to capital. We therefore target the mean of the cost shock $\bar{\varepsilon}$ to a capital share of $40 \%$. Vacancy posting costs $\kappa$ determine directly how many vacancies are posted and the contact rates in the search market. The contact rate determines the average job finding rate that we take from the data $\left(\pi_{u e}=0.052\right)$. To separately identify matching efficiency $\varkappa$ from vacancy posting costs $\kappa$, we use data on the average duration to fill a vacancy from the firm's perspective. In the IAB vacancy survey, the average time to fill a vacancy is 2.2 months. For the UI eligibility parameter $\gamma$, we target a share of $66 \%$ UI benefit recipients among all inflows to unemployment. The flow utility parameter of leisure $h$ determines the worker surplus from employment $\Delta$, and as part of the total

\footnotetext{
${ }^{18}$ We use GDP per capita for Germany as data on West German GDP are not available at a quarterly frequency.
} 
match surplus $S$, it determines the average probability of separating into unemployment (see eq. (11)). We match an average separation rate $\pi_{e u}=0.006$.

Matching the observed volatility of job creation over the business cycle is a challenge for this class of models (Shimer (2005), Hagedorn and Manovskii (2008)). The variation in acceptance rates $q(b, s)$ of workers over the business cycle provides additional amplification to job creation decisions (see eq. (9)). To impose discipline on the level and variation in acceptance rates, we target the estimated elasticity of job finding rates with respect to changes in unemployment benefits from the literature (Schmieder and Von Wachter (2016) for Germany). We use the elasticity of average acceptance probabilities with respect to changes in unemployment benefits $\frac{\partial q}{\partial b} \frac{b}{q}$ and target a value of 0.53 from Schmieder and Von Wachter (2016). ${ }^{19}$ For a given dispersion of non-pecuniary shocks, this elasticity pins down one of the means of the non-pecuniary shocks. We use it to pin down $\bar{\nu}\left(b_{3}\right)$. We impose the condition that recipients of unemployment assistance benefits $b_{2}$ and benefits at a subsistence level $b_{1}$ have the same mean of shocks $\bar{\nu}\left(b_{1}\right)=\bar{\nu}\left(b_{2}\right)$. This effectively results in different means for the short- and long-term unemployed. Hence, duration dependence in job finding rates is informative about the difference between $\bar{\nu}\left(b_{1}\right)$ and $\bar{\nu}\left(b_{3}\right)$. For the duration dependence, we use a difference in job finding rates between 6 and 12 months of $25 \% .{ }^{20}$ Very related is the identification of the parameter $\psi_{\nu}$ determining the dispersion of the non-pecuniary shock distribution. While we use the cross-sectional variation in job finding rates to determine means of the non-pecuniary shock distribution, we leverage the time series variation in job finding rates to identify $\psi_{\nu}$. We target a volatility of job finding rates that corresponds to 6.4 times the volatility of output. Similarly, we use the time series volatility of separation rates to identify the dispersion of cost shocks $\psi_{\varepsilon}$. We target a volatility of separation rates that corresponds to 7.8 times the volatility of output. The volatility of separations is higher than the volatility of job finding rates, in line with existing evidence (Jung and Kuhn (2014), Elsby et al. (2013)).

These elasticities are key when we change the unemployment insurance system. To see this, recall that a $1 \%$ change in the surplus of the match from a change in productivity works similar to a $1 \%$ change in the surplus from a change in the outside option. Hence, time series variation of transition rates are informative about the effects from structural changes in labor market institutions (Costain and Reiter (2008)).

\footnotetext{
${ }^{19}$ This elasticity of search $\frac{\partial q}{\partial b} \frac{b}{q}$ in the model is the percentage change in the acceptance probability of an unemployed worker receiving unemployment benefits with respect to a percentage change in the benefit level for given contact and separation rates.

${ }^{20}$ Mean job finding rates of these two benefit groups are computed from aggregate data between 1996 and 2004 on average durations in the respective group. We assume constant job-finding rates within each benefit type. To obtain the job finding rate of short-term benefit recipients, we further assume that they transit to long-term benefits after 12 months. We can then back out the implied job finding rate from the mean duration of the truncated distribution.
} 
For the skill process, we use the one-to-one relation between the average duration of short-term employment that we set to 3 years and the probability of skill accumulation $\alpha$. Similarly, we use the one-to-one relation between the share of long-term employed workers and the probability of labor market exit $\omega$. Short-term and long-term employed workers differ in their productivity levels $x_{1}$ and $x_{2}$. We exploit the documented separation rate differences between the two groups to pin down the skill difference $\Delta x=x_{2}-x_{1}$. We normalize $x_{1}$ and use the difference between short-term employed workers' separation rate of 0.014 and long-term employed workers' separation rate of 0.003 from Table 3 to determine the skill difference $\Delta x$.

Table 5: Parameters of the unemployment insurance system

\begin{tabular}{cccc}
\hline \multicolumn{2}{c}{ pre-reform } & \multicolumn{2}{c}{ post-reform } \\
\hline$b_{1}$ & 0.250 & $b_{1}$ & 0.250 \\
$b_{2}$ & 0.337 & $b_{2}$ & $\mathbf{0 . 2 5 0}$ \\
$b_{3}$ & 0.375 & $b_{3}$ & 0.371 \\
$\delta_{2}$ & 0.021 & $\delta_{2}$ & 0.021 \\
$\delta_{3}$ & 0.083 & $\delta_{3}$ & 0.083 \\
\hline
\end{tabular}

We calibrate parameters of the unemployment insurance system to independent evidence on replacement rates from the OECD. Parameters for the period before and after the reform are shown in Table 5. According to the OECD, a single worker with the average wage before 2004 received unemployment insurance benefits corresponding to $60 \%$ of the previous wage during the first year of unemployment and $53 \%$ of the previous wage for the following four years. We use these replacement rates to pin down $b_{3}$ and $b_{2}$. Consistently, we set $\delta_{3}$ to match an average duration of one year and $\delta_{2}$ to match an average duration of four years. For the subsistence level $b_{1}$, we match the average ratio of subsistence benefits to unemployment benefits over the period 1996 to 2002 based on data from the German Statistical Office (earlier data not available). The average ratio corresponds to $\frac{b_{1}}{b_{3}}$ in the model, and we fit it to be $67 \%$ as in the data $\left(\frac{b_{1}}{b_{3}}=0.67\right)$.

When exploring the effects of changes in the UI system from the Hartz reforms on labor market dynamics, we focus on the abolition of long-term unemployment benefits (unemployment assistance benefits). As in Krause and Uhlig (2012), we implement the reform in the model by setting long-term unemployment benefits $b_{2}$ to the level of subsistence social security benefits $b_{1}$, i.e., we set $b_{1}=b_{2}$. The duration parameter $\delta_{2}$ becomes irrelevant because transitions happen between states with the same benefit levels and mean 
utility shocks $\bar{\nu}\left(b_{1}\right)$ and $\bar{\nu}\left(b_{2}\right)$ are set identical across the two states in the calibration.

In the model, this change becomes effective in January 2006. As described above, the law became effective in January 2005, but the law scheduled the new benefit rules to affect workers only if they became unemployed after February 2006. In addition, a wide range of grandfathering rules and hardship clauses were provided with the law, such that it became only slowly applicable to all workers. We implement the complex and detailed legislation by gradually increasing the impact of the reform on labor market dynamics. Specifically, we use different policy functions based on linear approximation of the steadystate systems before and after the Hartz reforms. We assume a linear weighting scheme that spreads the implementation over four years so that the reform is fully effective in January 2010. ${ }^{21}$ When implementing the Hartz reforms in the model, we keep all other parameters except for the UI system constant over time.

\section{Results}

In the first step, we demonstrate the model's ability to match the dynamics of observed labor market flows over time. Dynamics in the model are driven by two sources: aggregate productivity fluctuations and the structural change of the UI system due to the Hartz reforms. As described before, parameters are only calibrated to match selected means and volatilities of labor market flow rates before the Hartz reforms and the Hartz reforms constitute a parsimonious change in the parameters of the unemployment insurance system. Figure 7 shows simulated times series of separation and job finding rates from the model together with the data counterparts of these series. We index all series to the pre-reform steady state that is matched as part of the calibration.

Figure 7(a) shows how closely the model fits the separation rate from the data. The empirical and simulated time series largely lie on top of each other. This is true both before the reform and after the reform. Except for a short period around 2010, the model matches the decrease in the separation rate and the dynamics during the financial crisis of 2008 very well. Overall, the fit for the average separation rate must be considered very close. Figure 7(b) shows the simulated job finding rate together with the data counterpart. Job finding rates before 2005 are again matched very closely. After the reform, the model matches the dynamics and level changes closely with the exception of a period between 2005 and 2009 when the model predicts a more immediate increase in job finding rates compared to the data. This is the transition period after the Hartz reforms when our

\footnotetext{
${ }^{21}$ We also tried implementing the reform directly with the only difference that the dynamics during the transition period are matched less well. Obviously, this assumption does not affect changes in steady states but only the behavior of the model during the transition phase. Hence, our key results do not depend on the specific implementation of the transition period.
} 
Figure 7: Fit for average labor market mobility (1993 - 2014)

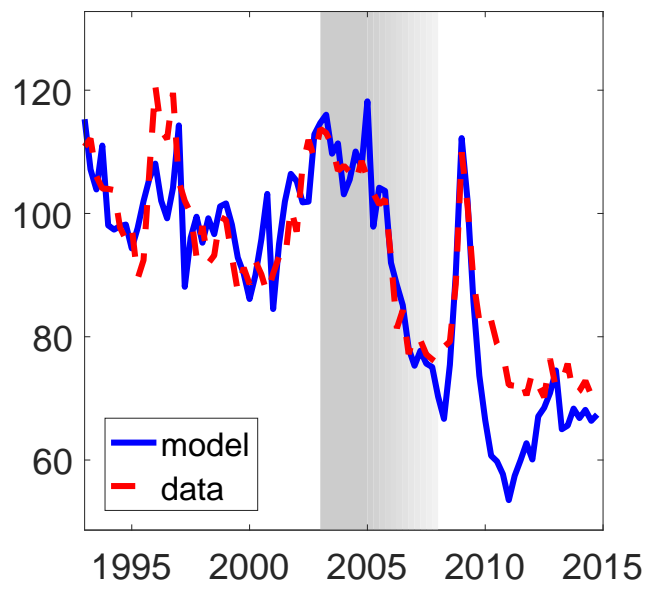

(a) separation rates

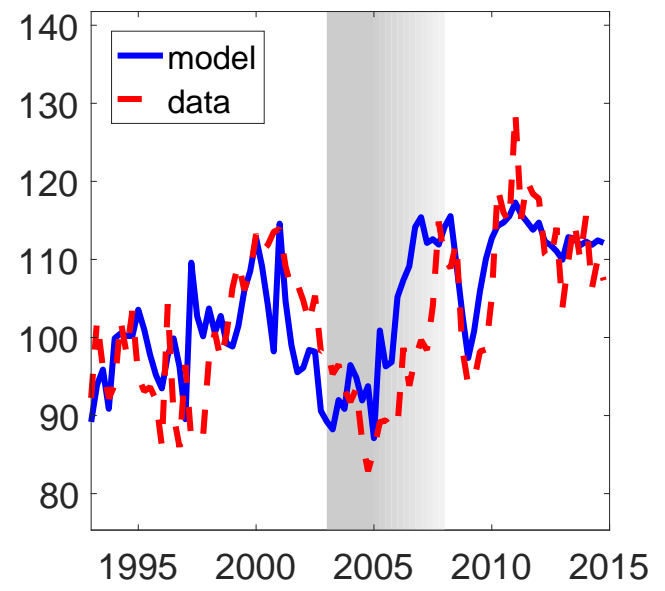

(b) job finding rates

Notes: Model fit 1993 - 2014. The blue solid lines mark the model prediction and the red dashed lines mark the respective flow rate in the SIAB microdata. The grey area marks the period 2003 to 2005 when the Hartz reforms were enacted. The fading out indicates the first transition years 2006 to 2008 after the reforms.

implementation of grandfathering rules and hardship cases is very rudimentary. However, what is important for our analysis below is that the changes in average rates between the pre-reform period and the post-reform period are matched almost exactly by the model.

Our empirical analysis uncovers large heterogeneity in changes in separation rates after the reform. Figure 8 demonstrates the model's ability to match such heterogeneity in changes in separation rates. As for the average separation rate, levels and level differences between short-term and long-term employed workers before the reform have been calibrated so that they are matched by construction. Heterogeneity in changes after the reform are untargeted and provide a check to the hypothesis of a causal relationship of the reform to the observed changes in separation rates. Results in Figure 8 support the hypothesis of a causal relationship from the reform to observed changes in labor market dynamics by demonstrating a close match of the heterogeneous responses in separation rates between the model and the data.

Figure 8(a) shows the simulated and empirical separation rates for short-term employed workers with employment durations of less than three years. The model matches the time series very closely including the volatility. Unlike for the average separation rates, heterogeneous volatilities of separation rates for short-term and long-term employed workers have not been part of the calibration, but are an endogenous prediction of the model. Over the long run, the model predicts a slightly lower decline in separation rates for short-term employed workers relative to the data (10\% vs. 20\%). Importantly, how- 
Figure 8: Fit for heterogeneity in labor market mobility (1993 - 2014)

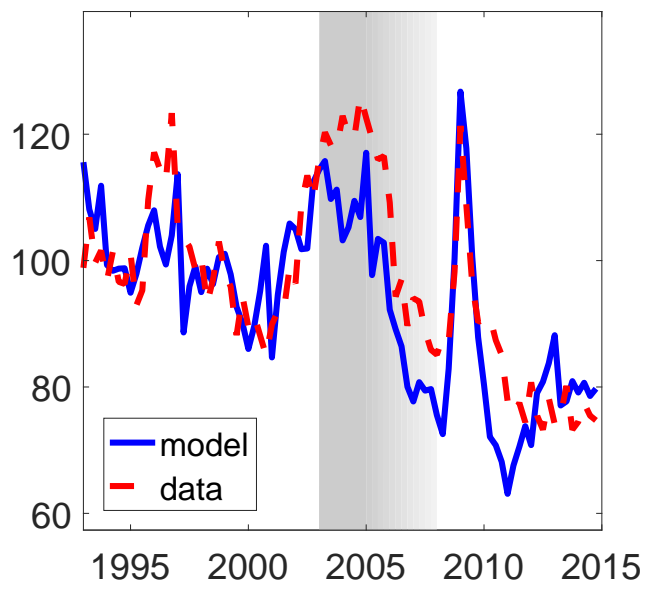

(a) separation rates $(\leq 3$ years $)$

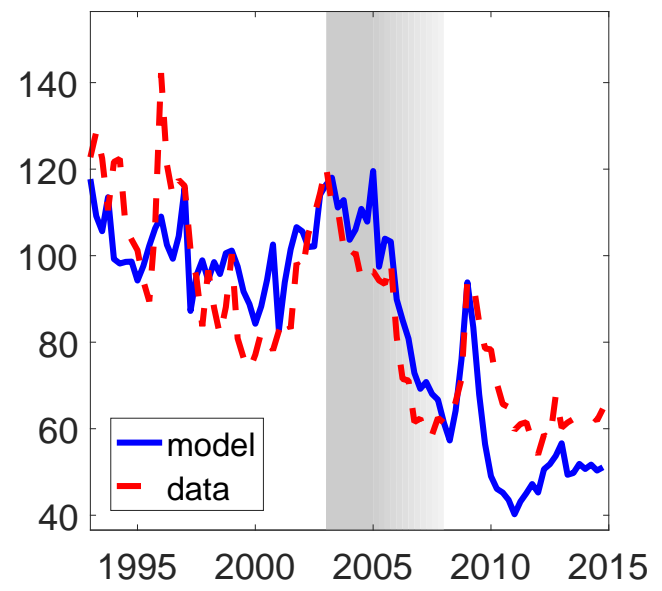

(b) separation rates ( $>3$ years)

Notes: Model fit for separation rates with low ( $\leq 3$ years, left panel) and high ( $>3$ years, right panel) employment duration from 1993 to 2014. The blue solid lines mark the model prediction and the red solid lines mark the respective flow rate in the SIAB microdata. The grey area marks the period 2003 to 2005 when the Hartz reforms were enacted. The fading out indicates the first transition years 2006 to 2008 after the reforms.

ever, like the data the model shows a substantially smaller decline in separation rates for short-term employed workers relative to the average in Figure 7(a).

Figure 8(b) compares the separation rates of long-term employed workers between the model and the data. We find that time series for the long-term employed workers are matched closely both in volatility and long-run trend. We find for the long-term employed workers that the model slightly overstates the decline in separation rates. Again, and importantly, we find that, in line with the argument that the reduction in long-term benefits was the causal mechanism behind the labor market miracle, the separation rates of long-term employed workers decline more than the average separation rates.

Overall, our parsimonious model of labor market dynamics captures the key empirical pattern for the changes in separation rates and job finding rates closely. The causal mechanism in the model is the decline of long-term unemployment benefits to subsistence levels. We will show, based on counterfactual simulations, that absent this change in the UI system, the model provides very counterfactual predictions for the evolution of labor market transition rates and unemployment rates.

The results of a large but heterogeneous response in separation rates after changes in non-work benefits in this section might also have implications beyond the case of the unemployment insurance system. Many social security reforms, such as changes in early retirement programs or disability insurance programs, likely show similar changes follow- 
ing changes in program benefits. Arguably, the responses of separation rates in these programs might be even larger due to the longer duration of benefit eligibility in these programs. Our results suggest that the elasticities of the decision to separate from employment in these programs with respect to changes in the attractiveness of program benefits on macroeconomic employment might be large. Neglecting such endogenous separation decisions when evaluating such programs can lead to very misleading evaluations of reforms.

\subsection{Counterfactual simulations}

This section further builds on our approach to establish a causal link from changes of the unemployment insurance system to the German labor market miracle relying on economic theory. We do this by running counterfactual model simulations in the absence of the labor market reforms. The simulated labor market dynamics of this counterfactual are strongly at odds with the data, while, as we have just demonstrated, the same model closely matches labor market dynamics in Germany for the two decades from 1994 to 2014 when the Hartz reforms are implemented. This finding provides further support for a causal effect from the Hartz reforms to the observed changes in the German labor market. Furthermore, the counterfactual simulation provides an approach to determine the contributions of structural changes and business-cycle fluctuations to changes in labor market dynamics.

The counterfactual simulation to demonstrate the impact of the Hartz reforms on labor market dynamics is simple and transparent. We keep all model parameters constant over time, including the parameters of the UI system, so that no structural change takes place. We also keep the aggregate shock series identical and feed in the previously estimated productivity shocks from the Kalman filter. This counterfactual simulation provides time series of separation rates, job finding rates, and unemployment rates in the absence of the Hartz reforms. Figure 9 shows the counterfactual simulation results for the time period from 1993 to 2014.

By construction, the time series from the baseline and the counterfactual in the period before the implementation of the Hartz reforms lie exactly on top of each other as we rule out any anticipation effects. ${ }^{22}$ After the implementation of the reform, the two simulated time series strongly diverge. Separation rates of the counterfactual remain high and fluctuate around their pre-reform level as shown by the red dashed line in Figure 9(a). Separation rates of the counterfactual simulation strongly spike during the

\footnotetext{
${ }^{22}$ Anticipation effects are likely small as the implementation of the reform happened on short notice. The parliament approved the law that became effective in January 2005 only in June 2004.
} 
Figure 9: Counterfactual model simulation absent Hartz reforms (1993 - 2014)

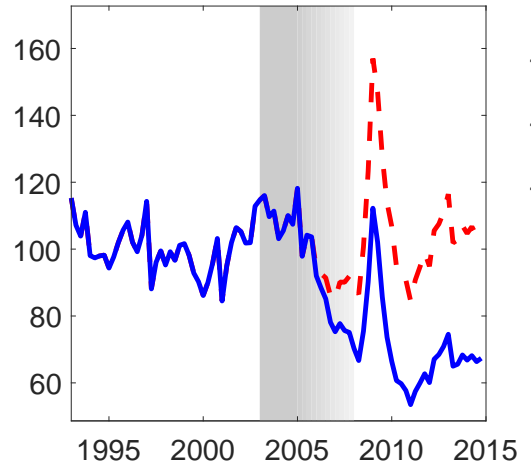

(a) Separation rates

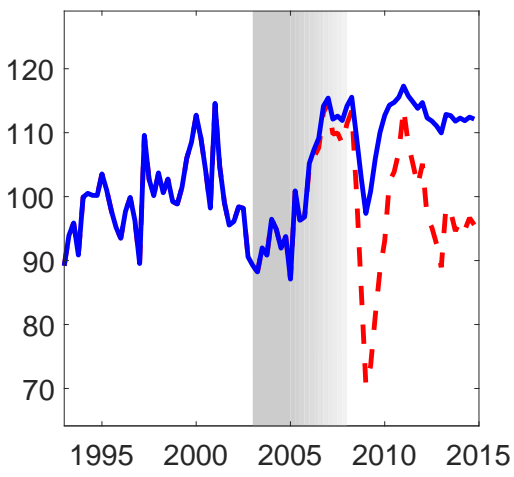

(b) Job finding rates

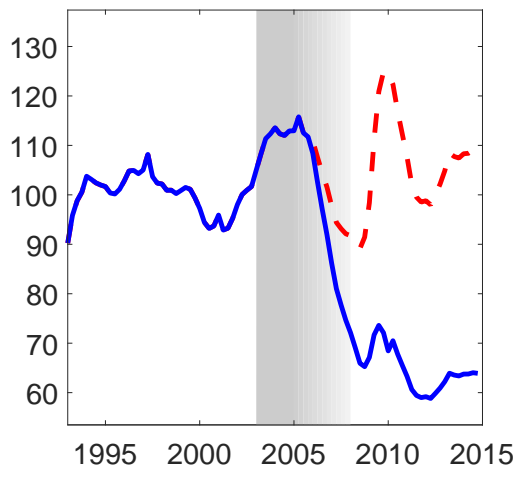

(c) Unemployment rates

Notes: Model simulations with and without the Hartz reforms for the period 1993 to 2014 . The blue solid lines show the model with the Hartz reforms and the red dashed lines show the counterfactual rate without policy change. The grey area marks the period 2003 to 2005 when the Hartz reforms were enacted. The fading out indicates the first transition years 2006 to 2008 after the reforms.

financial crisis of 2008, to almost $160 \%$ of their steady-state level. In the case of the reform, the separation rate still spikes but increases only to slightly more than $120 \%$ of the old steady-state level. Job finding rates in Figure 9(b) again evolve identically between baseline and counterfactual up to the implementation of the reform, when the two series start to diverge. In the new steady state with the reform, the job finding rates increase permanently by $10 \%$. Over time, the divergence is strongest during the financial crisis. In the counterfactual scenario, job finding rates plummet to around $70 \%$ of their steady-state level. In the case of the Hartz reforms, the job finding rate still decreases but only to a level slightly below its old steady-state level. The divergence of the separation and job finding rates manifests itself in very different dynamics of the unemployment rate. While unemployment in the baseline simulation with the Hartz reforms declines by $30 \%$ relative to the pre-reform steady state, the unemployment rate, by construction, stays put at its pre-reform level absent the reform. We find a marked difference in the evolution of unemployment rates between the two simulations during the financial crisis. The counterfactual simulation shows an increase in the unemployment rate of almost $30 \%$ over its long-run average, reminiscent of the typical European country and the United States during these years, which saw sharply and strongly rising unemployment rates. In the case of the implementation of the Hartz reforms, the rise in unemployment rates is substantially smaller compared to what most other countries experienced as the largest labor market crisis in decades. Unemployment rates increased about $10 \%$ over their new steady-state level that itself is $30 \%$ below the pre-reform level. The reason for the modest increase in unemployment after the reform is that while separation rates spike in both 
simulations, the relative decline in the job finding rate is much smaller in the case of the Hartz reforms. ${ }^{23}$ These strikingly different dynamics based on our theoretical labor market model provide a further argument for a causal relationship between the reduction in long-term unemployment benefits of the Hartz reforms and the German labor market miracle.

\subsection{Decomposing cyclical and structural changes}

We use the counterfactual simulations further to quantify the contribution of the business cycle to the decline in unemployment since 2004. Figure 9 shows that in 2004 all data series are away from their respective steady states. Our motivating evidence in Figure 1, like most of the public debate, focuses, however, on 2004 as a year of reference to assess the effect of the Hartz reforms on the labor market. Taking 2004 as reference, the decline in the unemployment rate between 2004 and 2014 contains some part that is due to the business cycle and not due to a structural change. We rely on the counterfactual simulation to isolate the business cycle component. Our decomposition approach is straightforward: We attribute all changes in the counterfactual simulation to the business cycle, and by subtracting these changes from the baseline model, we isolate the structural component of the changes in separation rates, job finding rates, and unemployment rates. Table 6 shows average unemployment, separation, and job finding rates in 2004 and 2014 from model simulations with and without the implementation of the Hartz reforms. The columns labeled change show the percentage change in the respective rates between 2004 and 2014. The change in the baseline case with the Hartz reforms compounds the business cycle effects with the effects from the structural reform, whereas the change in the case when the reform is not implemented results only from business cycle variation. We report the derived contribution of the business cycle in the last column of Table 6 .

Let's look first at columns of the baseline case with the implementation of the reform. The key driver of the lower unemployment rates is the decline in the separation rate by $30 \%$; the job finding rate increased by $17 \%$. Comparing these effects to the case absent the reform in the middle columns isolates the business cycle effect and shows that business cycle effects are small. The last column shows the constructed business cycle contributions to changes in the unemployment, separation, and job finding rates and we find that they never exceed $10 \%$. We conclude that business cycle effects are small and

\footnotetext{
${ }^{23}$ Germany's reliance on short-time work is oftentimes suggested as explanation for the low rise in unemployment rates during the Great Recession. Balleer et al. (2016) find that short-term work reduces the increase in unemployment rates by around $20 \%$ so that unemployment rates would have gone up by $36 \%$ rather than $30 \%$ without short-term work. Balleer et al. (2016) also find that the smaller reaction results mostly from lower separation rates while we explain the small reaction by a smaller decline in job finding rates in comparison with the counterfactual simulation.
} 
Table 6: Business cycle contribution

\begin{tabular}{lccccccc}
\hline & \multicolumn{3}{c}{ with reform } & \multicolumn{2}{c}{ absent reform } & Business cycle \\
& 2004 & 2014 & change & 2004 & 2014 & change & contribution \\
\hline $\begin{array}{l}\text { unemployment } \\
\text { rate }\end{array}$ & 10.2 & 6.5 & $-36.4 \%$ & 10.2 & 9.9 & $-3.7 \%$ & $10.0 \%$ \\
$\begin{array}{l}\text { job finding rate } \\
\text { separation rate }\end{array}$ & 0.7 & 0.5 & $-29.9 \%$ & 0.7 & 0.7 & $-1.2 \%$ & $3.9 \%$ \\
$\begin{array}{l}\text { separation rate } \\
\text { (short-term) }\end{array}$ & 1.6 & 1.3 & $-16.7 \%$ & 1.6 & 1.5 & $-1.4 \%$ & $8.6 \%$ \\
$\begin{array}{l}\text { separation rate } \\
\text { (long-term) }\end{array}$ & 0.3 & 0.2 & $-47.5 \%$ & 0.3 & 0.3 & $-1.7 \%$ & $3.6 \%$ \\
\hline
\end{tabular}

Notes: This table shows the unemployment and flow rates in the model before the reform (2004) and in the most recent year (2014). Columns 1-3 show the rates implied by a model with the Hartz reform, and columns 4-6 show the rates without the reform but the same business cycle shocks. The last column shows the relative contribution of the business cycle to the overall change in the respective variable.

of minor importance for the German labor market miracle.

\subsection{Germany and its neighbors}

We argue that the strong deviation of the counterfactual simulation in the absence of the Hartz reforms supports the claim of a causal relationship between the unemployment benefit changes of the Hartz reforms and the German labor market miracle. An important question is whether the quantitative size of the effects is realistic, i.e., whether the counterfactual provides a good description of what would have happened had the reforms not been implemented. Given that such a counterfactual evolution of the German labor market always remains unobserved, we apply an idea inspired by the control-treatment approach from the microeconometric literature. We use one of Germany's close neighbors, Austria, as a control group that was not treated by the Hartz reforms and compare the unemployment rates of Austria and Germany over time. This should be seen as being inspired by the idea of the control-treatment approach rather than a formal implementation.

Austria traditionally has business cycle dynamics that resemble those of Germany (see Figure 19 in the appendix). Although the business cycle dynamics for Germany and Aus- 
tria track each other closely, the level of the Austrian unemployment rate was on average $52 \%$ lower than the German unemployment rate in the decade before the Hartz reforms. We abstract from these level differences by adjusting the level of the Austrian unemployment rate using a multiplicative constant factor. ${ }^{24}$ For our comparison, we are interested in the relative changes in the unemployment rate over time that remain unaffected by this level adjustment. Figure 10 shows the evolution of the Austrian unemployment rate together with the simulated unemployment rates from our baseline model and from the counterfactual simulation absent the Hartz reforms. The comparison is striking. Looking at the evolution since 1993 in Figure 10(a), we find that the dynamics of the Austrian unemployment rate track the simulated unemployment rate of the counterfactual almost one-for-one, while the baseline simulation diverges after the implementation of the reform to a much lower level. Figure 10(b) zooms in on the evolution of the unemployment rate starting in 2008 and over the course of the Great Recession. Again, the results are striking. While the Austrian unemployment rate, like the counterfactual German unemployment rate, increases by almost $40 \%$ after four quarters into the recession, the unemployment rate from the baseline model increases by less than $20 \%$ four quarters into the Great Recession. Looking at the recovery, the Austrian and the counterfactual German unemployment rate revert only slowly back to pre-recession levels. Three years after the onset of the recession, they reach levels close to pre-recession times. As for the rise in the unemployment rate, we also find for the recovery that the Hartz reforms have reshaped the reaction of the German unemployment rate. After two years, the unemployment rate is already back to its pre-recession levels.

The comparison to the Austrian case provides further evidence for a causal relationship between the changes in the unemployment benefit system from the Hartz reforms and the German labor market miracle. Absent the reform, our model predicts a close comovement of Germany's unemployment rate with its Austrian counterpart. Germany's unemployment rate would be $50 \%$ higher today (9.9\% vs. $6.5 \%$ see Table 6 ). Comparison over the course of the Great Recession also highlights the changes in the business cycle dynamics of the German labor market after the reform.

\subsection{Reform's effects on wages}

Changes in workers' outside option affect the surplus split in the bargaining between workers and firms so that wages decline if unemployment benefits are cut. This mechanism plays the key role in Hagedorn et al. (2016), who quantify the effect of changes in unemployment benefits on the U.S. labor market during the Great Recession. This

\footnotetext{
${ }^{24}$ Data on the Austrian unemployment rate are taken from Eurostat. For 1993, we use OECD data to extend the Eurostat data series as the Eurostat data are only available from 1994 onward.
} 
Figure 10: Austrian unemployment rates and model simulations for Germany

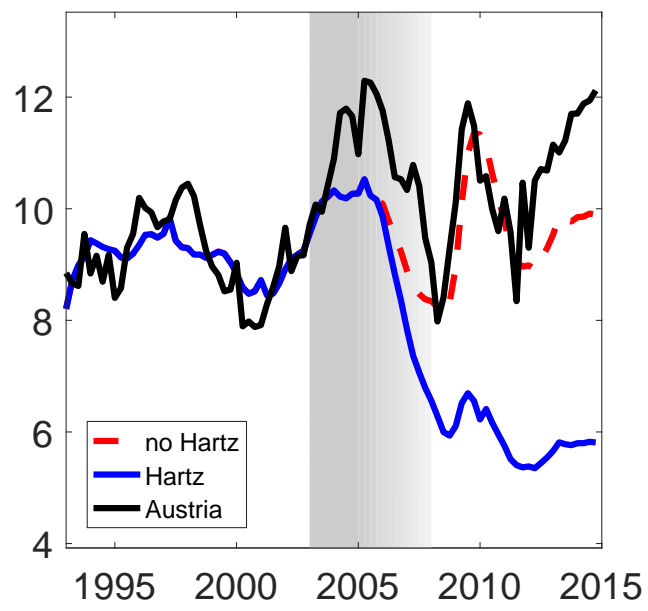

(a) unemployment rate

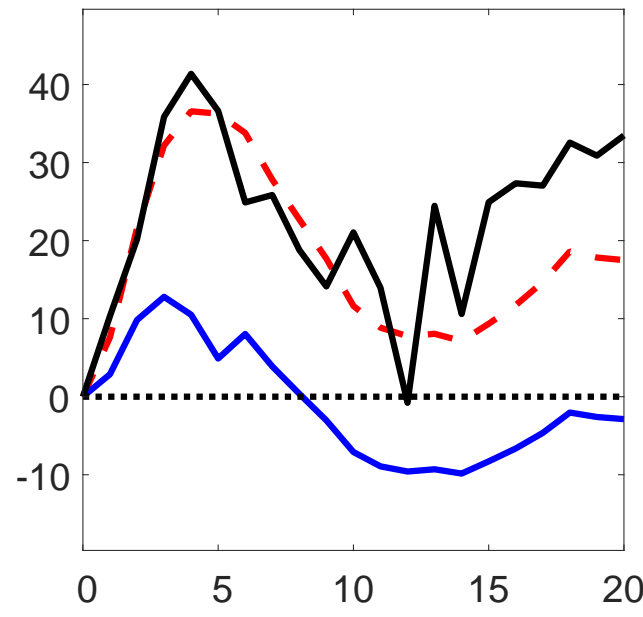

(b) unemployment change during Great Recession

Notes: Austrian unemployment rates in comparison to model simulations for Germany. The left panel shows unemployment rates in percent for Austria (level adjusted) and model simulations for Germany for the period 1993 to 2014. Black solid lines show Austrian unemployment rate, red dashed lines show counterfactual German unemployment rate from model simulation absent the Hartz reforms, and blue solid lines show simulation for Germany for the baseline model. The grey area marks the period 2003 to 2005 when the Hartz reforms were enacted. The fading out indicates the first transition years 2006 to 2008 after the reforms. The right panel shows the percentage increase in the unemployment rate for Austria and model simulations for Germany during the Great Recession. The onset of the Great Recession for Austria is 2008q2 and 2008q3 for Germany. The horizontal axis shows time in quarters relative to the onset of the recession.

mechanism is also present in our model so that wages of long-term employed workers fall by $1 \%$ in the new steady state after the reform. The outside option for short-term employed workers improves after the reform because benefits do not change, but job finding rates increase; hence, the same mechanism in our model leads to a wage increase of $0.8 \%$ for short-term employed workers. If wages decline, profits will increase, and firms will post more vacancies; as a consequence, job finding rates will increase and unemployment rates will decline. Our empirical evidence attributes a minor role to such a mechanism for the German labor market miracle by documenting only small changes in job finding rates. $^{25}$ Theoretically, two reasons explain the minor role of this channel for the German case. First, unemployment benefits for newly hired workers in the model do not change, so that the attractiveness to post vacancies hinges on indirect effects. Second,

\footnotetext{
${ }^{25}$ In their empirical analysis, Hagedorn et al. (2016) exploit cross-state variation in the United States. Such variation does not exist for the case of the German Hartz reforms, rendering the implementation of their approach infeasible for Germany. Absent the ability to exploit differential cross-sectional variation in labor market responses, it will require very strong assumptions on wage dynamics across different worker groups to isolate a reform effect on wage levels in the German data.
} 
job finding rates are empirically less sensitive to surplus changes in Germany (Jung and Kuhn (2014)); as a consequence, changes in unemployment benefits will affect job finding rates less (Costain and Reiter (2008)). Indeed, the relative contribution of job finding rates to unemployment volatility, which governs the importance of this mechanism for vacancy creation, is rather small in most OECD countries when compared to the United States (see Elsby et al. (2013)). This observation suggests that the relative importance of changes in job finding rates in the United States might be a particularity of the U.S. labor market and need not be a good description of the adjustment processes in other OECD countries. We provide the evidence for the German case.

While the reform's effect on wages is of minor importance for the vacancy creation mechanism, our theory has additional implications for the interaction of wage changes and separation rate changes brought about by the reform that this section explores. In our model, separation decisions are part of the bargaining between the worker and the firm. When benefits decline, workers want to trade off job stability in the form of lower separation rates against wages (Jung and Kuhn (2018)). Workers and firms will agree in the bargaining to stay together even after larger cost shocks, so that wages will decline. The ability to adjust wages and separation decisions in the bargaining implies a negatively sloped locus of bargained separation rates and wages across productivity levels: high-wage workers are in stable jobs. After a change in the outside option, this wage-separation rate locus will turn and become steeper. Long-term employed workers are willing to accept lower wages in order to reduce their separation rate. Hence, we should expect a stronger negative relationship between wages and separation rates after the reform. Uncovering a direct estimate of the elasticity from the data is intricate because of many confounding factors on wage growth. We will therefore focus on verifying that the qualitative model predictions can be found in the data. We follow the approach in Jung and Kuhn (2018) based on residual wage differences and regress the probability of separating into unemployment for individual $i$ over the next six months $\pi_{e u, i}^{6}$ on the contemporaneous (log-)wage $\log \left(w_{i, 0}\right)$ controlling for worker observables $X_{i}$

$$
\pi_{e u, i}^{6}=\alpha+\beta \log \left(w_{i, 0}\right)+\gamma X_{i}
$$

For the regression, worker characteristics are observed contemporaneously with the wage. The vector $X_{i}$ contains dummies for gender, 10-year age brackets, education levels, and time and industry dummies; $\log \left(w_{i, t}\right)$ refers to average daily earnings. ${ }^{26}$ The dependent variable $\pi_{e u, i}^{6}$ is a binary variable that is equal to one if the worker separates into unemployment at least once over the next six months. The coefficient of interest $\beta$ corresponds

\footnotetext{
${ }^{26}$ We focus only on full-time workers for this regression.
} 
to the elasticity of separation rates with respect to wages after dividing by the average separation rate $\bar{\pi}_{e u}^{6}$. The approach estimates the effect of residual wage differences as resulting from productivity differences and their effect on separation rates.

Table 7: Wages and separation rates

\begin{tabular}{lccc}
\hline period & $\bar{\pi}_{e u}^{6}$ & $\beta$ & elasticity \\
\hline pre-reform & 0.020 & $-0.020^{* * *}$ & -0.99 \\
post-reform & 0.013 & $-0.017^{* * *}$ & -1.28 \\
\hline
\end{tabular}

Notes: Regression results for the relationship between wages and separation rates before and after the Hartz reforms. The column labeled $\bar{\pi}_{e u}^{6}$ shows the average 6 -month separation rate. The column labeled $\beta$ shows the regression coefficient from equation (12). The last column reports the implied elasticity of separation rates on wages. See text for further details.

Table 7 reports the key regression coefficient $\beta$ for the period before the Hartz reforms (1993-2002) and after the reforms (2008-2014). The last column reports the implied elasticity of separation rates with respect to wages. Before the reform, we find an elasticity of -0.99 so that a (residual) productivity increase associated with a $1 \%$ wage increase reduces the separation rate by $1 \%$. This elasticity increases by almost one third to -1.28 after the Hartz reforms. Hence, workers choose a stronger trade-off between wages and job stability. This stronger trade-off between wages and separation rates is predicted by theory and provides further support for our proposed mechanism. ${ }^{27}$

\subsection{Welfare effects}

Our empirical and theoretical analysis demonstrates that changes in separation rates have been the driver of the German labor market miracle starting in the mid-2000s. We document and explain why the decline in separation rates has not been uniform in the population and that long-term employed, high-wage workers saw the strongest decline in their separation rates in reaction to the reform. Job finding rates increased, and thereby, the probability that both short- and long-term unemployed can find jobs and enter into employment. Our structural model allows us to investigate the welfare consequences of these changes for the different groups of workers. We derive welfare consequences as the consumption equivalent variation in steady-state consumption for a worker, i.e., we quantify a worker's willingness to pay to avoid the reform. We compute welfare consequences

\footnotetext{
${ }^{27} \mathrm{We}$ also ran a logit regression that directly estimates the elasticities. The estimated elasticities in terms of level and change are similar to the case of the linear regression. We estimate an elasticity of -0.87 before and -1.06 after the reforms.
} 
by relying on a steady-state comparison for all worker types: short- and long-term employed workers and workers in each of the three tiers of the unemployment insurance system. ${ }^{28}$ Note that this equivalent variation is uncompensated in the sense that due to lower unemployment after the reform, the government could redistribute gains from the reform. Our equivalent variation is before any redistribution and indicates the compensation necessary to make workers of each group indifferent between implementation of the reform and not implementing it.

Table 8: Welfare effects from the unemployment insurance reform

\begin{tabular}{lccccc}
\hline & \multicolumn{2}{c}{ employed } & \multicolumn{3}{c}{ unemployed } \\
\hline $\begin{array}{l}\text { worker } \\
\text { group }\end{array}$ & $\begin{array}{c}\text { short-term } \\
\text { employed }\end{array}$ & $\begin{array}{c}\text { long-term } \\
\text { employed }\end{array}$ & $\begin{array}{c}\text { social } \\
\text { assistance }\end{array}$ & $\begin{array}{c}\text { unemployment } \\
\text { assistance }\end{array}$ & $\begin{array}{c}\text { unemployment } \\
\text { benefits }\end{array}$ \\
$\begin{array}{l}\text { equivalent } \\
\text { variation }\end{array}$ & $0.11 \%$ & $0.64 \%$ & $0.03 \%$ & $2.11 \%$ & $1.18 \%$ \\
\hline
\end{tabular}

Notes: Welfare effects of the reform expressed as consumption equivalent variation for avoiding the implementation of the unemployment insurance reform.

Table 8 shows the welfare effects for the different groups of workers. We find the largest welfare losses for former recipients of unemployment assistance benefits, with a consumption equivalent variation larger than $2 \%$. Such a large welfare loss likely explains the grandfathering and hardship regulation that accompanied the reform. Note that we compare here steady states so that, even in our model with the staggered implementation, the welfare effects including the transition would be lower for this group. The group with the second largest welfare losses has been the unemployed, with an equivalent variation of $1.2 \%$. Unemployed workers receiving social assistance benefits experience hardly any welfare effect because their benefits remain unchanged by the reform. The non-zero effect results from an indirect effect from lower wages after skill accumulation in the case of re-employment. Turning to the employed, we find much larger effects for the long-term employed compared to short-term employed workers. The group of workers with very low separation rates (see Table 3) experiences a welfare loss corresponding to a consumption equivalent variation of $0.6 \%$. This group corresponds to more than $60 \%$ of all employed workers in the German labor market and has very low separation rates. The low separation rates might suggest that this group is the least affected by the reform, yet we find large welfare losses for them. The reason is very intuitive and closely connected to the causal mechanism of this paper. Welfare effects are large because the outside option for

\footnotetext{
${ }^{28}$ The assumption of risk neutrality leads to simple formulas for the consumption equivalent variation. Denote the value function before the reform by $V_{0}$ and after the reform by $V_{1}$; then the consumption equivalent variation is $\Delta=\frac{V_{0}-V_{1}}{V_{1}}$.
} 
these workers deteriorates most strongly with the abolition of long-term, wage-dependent unemployment benefits. Hence, a group of almost two-thirds of the German labor market experienced large welfare losses from the reform. These losses remained largely uncompensated in the aftermath of the reform and might therefore explain the large discontent with the reform by large parts of the German electorate.

These results might have important implications beyond the specific case of the German Hartz reforms for reform proposals in other European countries. The results suggest that the political feasibility of UI reforms might critically depend on the compensation of the large group of long-term employed workers with secure jobs who, at first glance, might appear very detached from the topic of unemployment benefit reforms.

\subsection{Alternative explanations}

In this paper, we provide empirical evidence in connection with economic theory to argue that the cause of the German labor market miracle has been the unemployment insurance reform that was part of the Hartz reforms in the mid-2000s. The German labor market miracle (Burda and Seele (2016)) has been widely studied, and various narratives have been proposed in addition to the ones that highlight changes in job finding rates as a key driver. We provide a short summary of our investigation regarding such alternative explanations and relegate details to Appendix E. Maybe the most prominent narrative comes from Dustmann et al. (2014), who argue that Germany's unit labor costs and wages were declining relative to other European countries even before the Hartz reforms. They point to declining union power as a possible source for the decline. From the viewpoint of economic theory, wage trends alone are hard to interpret and need to be discussed relative to productivity trends and trends in the outside option. We show in E.1 that the declining trend in unit labor costs in Germany is hard to reconcile with the relative evolution of the unemployment rate in Germany relative to other European countries. In particular, this explanation struggles to account for the increase in unemployment rates in Germany during the 1990s and the sudden reversal after 2005. Another related narrative focuses on globalization and an export-demand-driven boom in Germany (see Dauth et al. (2016) for some evidence on globalization effects in export- and importexposed industries). Looking at industries by export exposure following the industry classification used by Dauth et al. (2016), we show in Appendix E.2 that separation rate changes in industries classified as export-exposed behave similarly to the ones classified as non-exposed, suggesting that export exposure is likely not the main driver of the decline in separation rates. Generally, explanations that, through different channels, affect aggregate GDP growth will be already captured by our analysis as we include 
aggregate GDP changes in our analysis. Section 4.2 provides an upper bound of the contribution of these effects. Finally, we study whether the Hartz reforms have affected in particular long-term unemployed workers (see Klinger and Rothe (2012) for a more extensive empirical analysis). Reducing long-term unemployment was one of the explicit goals of the reform. We show in Appendix E.3 that the share of long-term unemployed remained largely constant between the pre- and post-reform period. Together with the evidence on job finding rates, this suggests that the effects via a reduction in long-term unemployment are likely to be very modest.

\section{Conclusions}

What hides behind the German labor market miracle? This paper combines an empirical analysis of microdata on worker flows with economic theory on labor market dynamics to provide an answer to this question. We trace the German labor market miracle back to the reform of the German unemployment insurance system that happened during the Hartz reforms in Germany in the mid-2000s. Our analysis highlights changes in separation rates after the unemployment benefit reform as the quantitatively important channel through which the unemployment insurance system affects unemployment rates and labor market dynamics. We contribute thereby to a key question of labor market research.

We provide evidence that a decrease in separation rates after the reform explains $76 \%$ of declining unemployment. Existing studies on the German labor market miracle leave this empirical fact unexplained by focusing on changes in job finding rates. The reduction in separation rates is heterogeneous, with long-term employed, high-wage workers being most affected. We use economic theory to causally link our empirical findings to the abolition of long-term, wage-dependent unemployment benefits that was implemented by the Hartz reforms. Using our quantitative labor market model, we find that absent the reform, unemployment rates would be $50 \%$ higher today. We also find a close comovement of the German and Austrian unemployment rates over the last decade for a counterfactual without the labor market reforms in Germany.

Exploring the welfare consequences of the labor market reforms, we find that long-term employed high-wage workers suffered substantial welfare losses in the absence of compensating transfers. This worker group accounts for almost two-thirds of the German workforce. The separation rates of these workers are the lowest in the labor market, and it might therefore appear as if these workers are very detached from any changes in the unemployment insurance system. We show that this is not the case and that, in hindsight, their welfare losses might explain the discontent of a large part of the German electorate with these reforms. 
Our results have two important implications for labor market reforms. The first is related to future labor market reforms in other European countries as they have been widely discussed after observing Germany's labor market miracle. For these reforms to be politically feasible, the welfare effects must be a key part of the consideration, and compensation schemes must be designed to avoid discontent in large parts of the electorate. Second, the strong reaction of separation rates after changes in non-work benefits highlights the importance of this channel for other labor market reforms such as early retirement programs or disability insurance programs. 


\section{References}

Antoni, Manfred, Andreas Ganzer, and Philipp vom Berge, "Sample of Integrated Labour Market Biographies (SIAB) 1975-2014," Technical Report, Data report 04/2016, Institute for Labor Market Research (IAB), Nuremberg 2016.

Autor, David, David Dorn, and Gordon Hanson, "The China syndrome: Local labor market effects of import competition in the United States," American Economic Review, 2013, 103, 2121-68.

Baily, Martin, "Some aspects of optimal unemployment insurance," Journal of Public Economics, 1978, 10, 379-402.

Balleer, Almut, Britta Gehrke, Wolfgang Lechthaler, and Christian Merkl, "Does short-time work save jobs? A business cycle analysis," European Economic Review, 2016, 84, 99 - 122. European Labor Market Issues.

Burda, Michael and Stefanie Seele, "No Role for the Hartz Reforms? Demand and Supply Factors in the German Labor Market 1993-2014," SFB 649 Discussion Paper, 2016.

Chetty, Raj, "A general formula for the optimal level of social insurance," Journal of Public Economics, 2006, 90, 1879-1901.

Chodorow-Reich, Gabriel and Loukas Karabarbounis, "The Limited Macroeconomic Effects of Unemployment Benefit Extensions," Working paper, 2016.

Costain, James and Michael Reiter, "Business Cycles, Unemployment Insurance, and the Calibration of Matching Models," Journal of Economic Dynamics and Control, 2008, 32 (4), $1120-1155$.

Dauth, Wolfgang, Sebastian Findeisen, and Jens Suedekum, "Adjusting to Globalization - Evidence from Worker-Establishment Matches in Germany," mimeo, Duesseldorf Institute for Competition Economics, 2016.

Dustmann, Christian and Costas Meghir, "Wages, Experience and Seniority," Review of Economic Studies, 2005, 72 (1), 77-108.

_ , Bernd Fitzenberger, Uta Schönberg, and Alexandra Spitz-Oener, "From sick man of Europe to economic superstar: Germany's resurgent economy," The Journal of Economic Perspectives, 2014, 28 (1), 167-188. 
Elsby, Michael WL, Bart Hobijn, and Ayşegül Şahin, "Unemployment dynamics in the OECD," Review of Economics and Statistics, 2013, 95 (2), 530-548.

Hagedorn, Marcus and Iourii Manovskii, "The Cyclical Behavior of Equilibrium Unemployment and Vacancies Revisited," American Economic Review, 2008, 98 (4), 1692-1706.

_, Fatih Karahan, Kurt Mitman, and Iourii Manovskii, "The Macro and Microeffects of Macroeconomic Policy," Working paper, 2016.

Hartung, Benjamin, Philip Jung, and Moritz Kuhn, "Etiopathology of Europe's Sick Man: Worker Flows in Germany, 1959-2016," 2016, (10341).

Hertweck, M. and O. Sigrist, "The Ins and Outs of German Unemployment: A Transatlantic Perspective," Oxford Economic Papers, 2015, 67 (4), 1078-1095.

Hopenhayn, Hugo and Juan Pablo Nicolini, "Optimal Unemployment Insurance," Journal of Political Economy, 1997, 105 (2).

Jäger, Simon, Benjamin Schoefer, and Josef Zweimüller, "Marginal jobs and job surplus: Evidence from separations and unemployment insurance," Technical Report, Working Paper 2018.

Jung, Philip and Moritz Kuhn, "Labour market institutions and worker flows: comparing Germany and the US," The Economic Journal, 2014, 124 (581), 1317-1342.

_ and _, "Earnings Losses and Labor Mobility Over the Life Cycle," The Journal of the European Economic Association, 2018.

Katz, Lawrence F and Bruce D Meyer, "The impact of the potential duration of unemployment benefits on the duration of unemployment," Journal of Public Economics, 1990, $41(1), 45-72$.

Klinger, Sabine and Enzo Weber, "Decomposing Beveridge Curve Dynamics by Correlated Unobserved Components," Oxford Bulletin of Economics and Statistics, 2016, 78 (6), 877-894.

— and Thomas Rothe, "Der Rueckgang der Langzeitarbeitslosigkeit in Deutschland: Ein Erfolg der Hartz-Reformen oder konjunktureller Effekt," Schmollers Jahrbuch, 2012, $132(1), 89-121$.

Krause, Michael U and Harald Uhlig, "Transitions in the German labor market: Structure and crisis," Journal of Monetary Economics, 2012, 59 (1), 64-79. 
Krebs, Tom and Martin Scheffel, "Macroeconomic evaluation of labor market reform in Germany," IMF Economic Review, 2013, 61 (4), 664-701.

Launov, Andrey and Klaus Wälde, "Estimating incentive and welfare effects of nonstationary unemployment benefits," International Economic Review, 2013, 54 (4), $1159-1198$.

Millard, Stephen P. and Dale T. Mortensen, "The unemployment and welfare effects of labour market policy: A comparison of the USA and the UK," in Dennis J. Snower and Guillermo de la Dehesa, eds., Unemployment Policy: Government Options for the Labour Market, Cambridge University Press, 1997, pp. 545-572.

Murtin, Fabrice and Jean-Marc Robin, "Labor market reforms and unemployment dynamics," Labour Economics, 2016.

Pissarides, Christopher A, Equilibrium Unemployment Theory, MIT press, 2000.

Schmieder, Johannes F and Till Von Wachter, "The effects of unemployment insurance benefits: New evidence and interpretation," Annual Review of Economics, 2016, $8,547-581$.

Shavell, Steven and Laurence Weiss, "The Optimal Payment of Unemployment Insurance Benefits over Time," Journal of Political Economy, 1979, 87 (6), 1347-1362.

Shimer, Robert, "The Cyclical Behavior of Equilibrium Unemployment, Vacancies, and Wages: Evidence and Theory," American Economic Review, 2005, 95 (1), 25-49.

_ , "Reassessing the ins and outs of unemployment," Review of Economic Dynamics, $2012,15(2), 127-148$.

Steffen, Johannes, "Sozialpolitische Chronik," Arbeitslosenversicherung (seit 1969). Arbeitnehmerkammer Bremen. Bremen, 2008.

Tuit, Sanders and Jan van Ours, "How changes in unemployment benefit duration affect the inflow into unemployment," Economic Letters, 2010, 109 (2), 105-107. 


\section{A The Hartz reforms}

The Hartz reforms in Germany consisted of four legislative packages (Hartz I - Hartz $I V$ ) that became effective between 2003 and 2005. The first two parts of the reform were enacted in 2003 and contained several steps: Hartz $I$ changed the legal framework for temporary work, making it more attractive for firms to hire temporary workers by lifting restrictions. Hartz II changed the regulations for marginal employment and introduced an additional form of social security tax-favored employment (midi-jobs) and subsidies for unemployed workers starting their own business.

Hartz III was enacted in 2004 and restructured the federal employment agency. In particular, placement agencies (Arbeitsämter) and social security offices (Sozialämter) were combined into single institutions (Arbeitsagenturen). Newly created job centers were set up and case managers supported the job search of unemployed workers.

Hartz IV was enacted in 2005. This part of the reform constituted the large overhaul of the German UI system that is the focus of our investigation. It is also the publicly most debated and controversial part of the reforms because it substantially reduced unemployment benefits for several groups of workers by abolishing the system of unemployment assistance benefits (Arbeitslosenhilfe). Before the reform, unemployment assistance could be received for several years after unemployment benefits expired, depending only on some weak eligibility criteria. Workers who were not eligible for unemployment assistance received a minimum subsistence level (Sozialhilfe) that included rent payments but was not linked to previous wages. Hartz IV abolished the wage-dependent benefits for the long-term unemployed so that after the reform they would receive the minimum subsistence level (Arbeitslosengeld II). Unemployment benefits (Arbeitslosengeld I) remained largely unchanged.

The duration of eligibility for unemployment benefits depends on past employment under social security legislation and changed simultaneously with the Hartz reforms. The changes became effective in February 2006. Before the change, workers were eligible for age-specific maximum benefit durations ranging from 12 months for workers younger than 45 years up to 32 months for workers 57 years and older (see Figure 3). The general rule was that two months of employment resulted in one month of benefit eligibility up to the maximum eligibility threshold. Hence, for most workers two years of employment guaranteed maximum eligibility. After the reform, the maximum benefit duration was set at one year, and three months of employment were necessary for one additional month of eligibility. For workers 55 and older, the maximum duration was cut to 18 months. ${ }^{29}$ We

\footnotetext{
${ }^{29}$ In 2009 this change was partly reversed again. Workers of age 50, 55 and 58 could then receive
} 
exploit this variation in our empirical analysis. The fact that this change only became effective in 2006 and the fact that additional grandfathering and hardship regulations were introduced motivate our reasons for introducing the reform with a transition phase in our quantitative model.

To summarize, the Hartz IV reform transformed the former three-tier system of unemployment benefits, unemployment assistance, and subsistence benefits into a two-tier system of unemployment benefits and subsistence benefits.

\section{B Data details}

\section{B.1 Sample selection}

In our baseline analysis, we focus on the West German labor market from 1993 to 2014 in order to reduce the impact of the German reunification on unemployment and transition rates. We restrict our sample to persons who had employment or unemployment spells only in West Germany. We also drop persons for whom the SIAB does not contain any information on their geographic location or employment status. We provide results for East Germany as part of our sensitivity analysis in Section C. 4 of this appendix.

\section{B.2 Definition of labor market states}

We define a worker as employed if the worker is full- or part-time employed or employed as an apprentice. We require current wages to be non-zero to exclude dormant employment relationships, for example, workers on maternity leave. We also exclude marginally employed workers in our baseline definition of employment and define them as being unemployed if they have a parallel unemployment spell and as not in the labor force if there is no parallel spell. The SIAB microdata are derived from social security records with information on dependent employment under social security legislation, so that we do not cover self-employed workers and public servants (Beamte) in our employment definition.

We define a worker as unemployed if the person is registered as unemployed at the federal employment agency. ${ }^{30}$ The SIAB microdata provide comprehensive information on unemployment registrations from 2000 onward. For the period 1993 to 2000, we rely on information on benefit-recipient status to define workers as unemployed. This includes all workers who receive unemployment benefits and unemployment assistance. To construct worker flow rates for the entire period 1993 to 2014, we extend the registration-based worker flow rates backward starting in 2000 using the growth rates of benefit-based worker

benefits for up to 15,18 , and 24 months again.

${ }^{30}$ Workers can remain registered as unemployed as long as they work less than 15 hours per week. 
flow rates for the period 1993 to 2000. Extending the time series using growth rates avoids level breaks in the series but preserves the cyclical properties of worker flow rates.

Figure 11: Unemployment rates 2000-2014

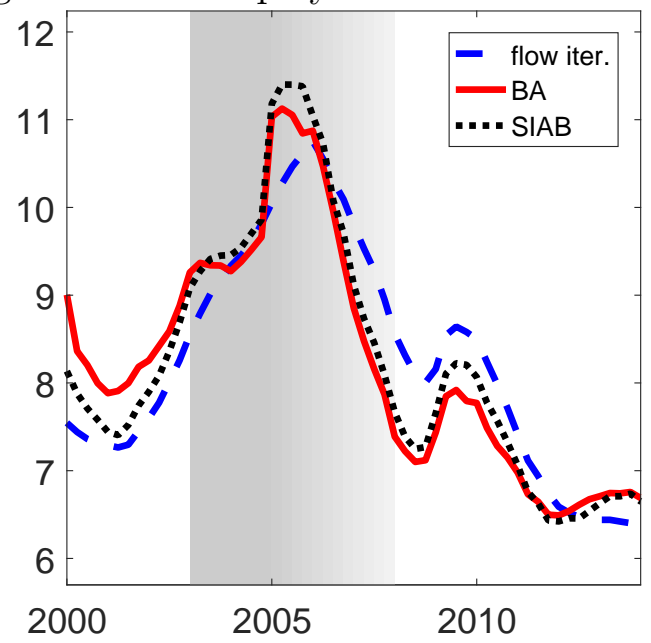

Notes: Red solid line displays the registered unemployment rate in the SIAB data for West Germany 2000-2014. The blue dashed line displays the unemployment rate obtained by iterating forward the SIAB unemployment rate in January 2000 using monthly separation and job finding rates: $u_{t+1}=u_{t}\left(1-\pi_{u e, t}\right)+\left(1-u_{t}\right) \pi_{e u, t}$. The grey area marks the period 2003 to 2005 when the Hartz reforms were enacted. The fading out indicates the first transition years 2006 to 2008 after the reforms.

In our empirical analysis, we study the evolution of worker flow rates to uncover changes in the underlying dynamics of the inflows and outflows to unemployment. Hence, what is most important for our analysis is that the constructed worker flow rates account for the changes in the unemployment rate over time. Figure 11 shows the unemployment rate from the SIAB microdata (black dotted line) and the unemployment rate from the federal employment agency (red solid line) as in Figure 1. In addition, we construct a flow-based unemployment rate using the law of motion of a two-state approximation of unemployment dynamics

$$
u_{t+1}=u_{t}\left(1-\pi_{u e, t}\right)+e_{t} \pi_{e u, t} .
$$

where $e_{t}$ denotes the employment rate of workers covered by social security legislation (see Section 2.2). Such a two-state approximation of unemployment dynamics also underlies our labor market model in Section 3. We use this law of motion to iterate forward the unemployment rate over time. Changes in the unemployment rate using this flow-based approach are only determined by changes in separation rates $\pi_{e u, t}$ and job finding rates $\pi_{u e, t}$. The unemployment rate from this flow-based approach is shown as the blue dashed line in Figure 11. We find that this unemployment rate closely tracks the dynamics of the aggregate unemployment rate. Hence, changes in the transition rates based on these 
definitions and construction account for the observed changes in the unemployment rate over time and are therefore informative about the drivers of declining unemployment.

\section{Sensitivity analysis}

This section provides a sensitivity analysis of the empirical analysis of Section 2. We consider in Section C.1 a sample where we do not apply the inflow correction described in Section 2.2. Related to skipping the inflow correction, we explore in Section C.2 how much changes in the composition of the employed have contributed to the changes in the separation rates over time. We provide a further detailed discussion of heterogeneity in separation rate changes by age and employment duration in Section C.3. In Section C.4, we compare East and West German worker flow rates. In the main part of the paper, we restrict attention to West Germany. Section C.5 includes marginally employed workers in the definition of employment. In the main part, we do not include marginally employed workers in the definition of the employment state. Section C.6 looks at the effect on job finding rates from changes in how workers in active labor market programs are counted before and after the reform.

\section{C.1 Worker flows without inflow correction}

Figure 12 shows separation and job finding rates for the baseline sample with the inflow correction and for a sensitivity sample where we skip the inflow correction. 
Figure 12: Separation and job finding rates (1993 - 2014)

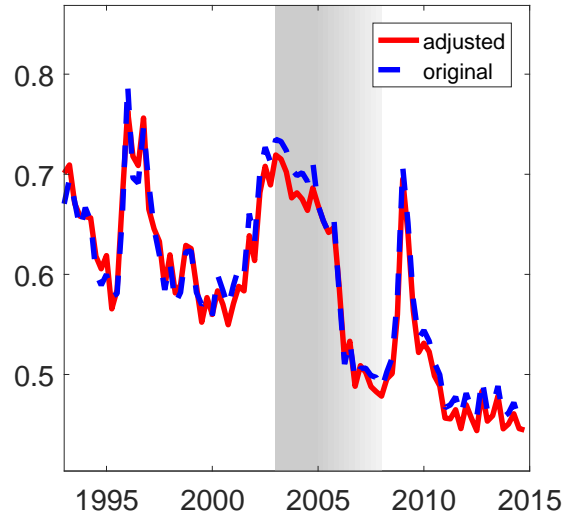

(a) Separation rate

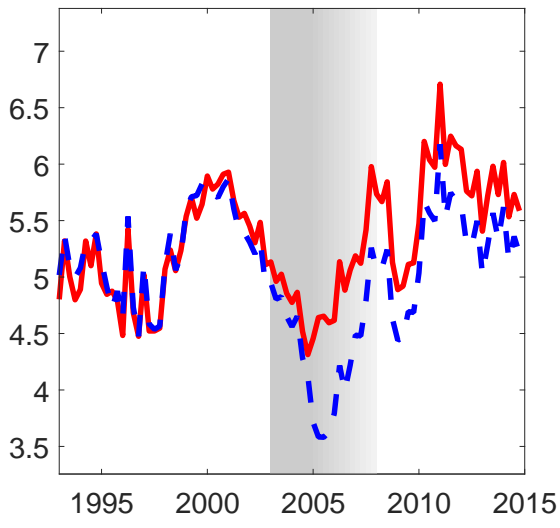

(b) Job finding rate

Notes: Left panel shows separation rates in percentage points. Right panel shows the job finding rate in percentage points. The red solid lines exclude non-employed entering the unemployment pool in the first half of 2005 who did not become employed until the end of 2006 (inflow correction). The blue dashed lines show the separation rates without inflow correction. Horizontal axis shows the years from 1993 to 2014. The grey area marks the period 2003 to 2005 when the Hartz reforms were enacted. The fading out indicates the first transition years 2006 to 2008 after the reforms.

Looking at separation rates in Figure 12(a), we see that the inflow correction hardly affects separation rates. The reason is that those workers whom we exclude with our inflow correction are only weakly attached to the labor market. In the case where they become employed, they constitute only a negligible fraction of total employment so that separation rates remain almost unaffected. This is not true for job finding rates in Figure 12 (b). Job finding rates are almost 20\% lower in January 2005 in the full sample compared to the inflow-corrected sample. This difference decreases over time but remains sizable even at the end of our sample in 2014. Job finding rates before 2005 remain largely unaffected in line with the idea that these workers are only weakly attached to the labor force. Hence, if we do not apply the inflow correction the increase in job finding rates would be smaller and the contribution of the decreasing separation rate to the decrease in the unemployment rate would be even larger.

\section{C.2 Controlling for composition}

Our empirical analysis in Section 2 and Section C.3 of this appendix documents substantial heterogeneity in separation rates across worker groups. One potential reason for decreasing separation rates that would be unrelated to the UI reform could be changes in the composition of worker groups with different separation rates over time. To assess the quantitative importance of composition effects on separation rates, we run a linear 
probability model of separation rates on a large set of observable worker characteristics. We run the following regression

$$
\mathbf{1}_{e u, i, t}=X_{i, t} \beta_{t}+\varepsilon_{i, t}
$$

where $\mathbf{1}_{e u, i, t}$ denotes an indicator function that is one if in year $t$ we observe a transition from employment into unemployment of individual $i . X_{i, t}$ denotes a vector with dummies for individual characteristics of individual $i$ in year $t, \beta_{t}$ denotes the coefficient vector that we allow to vary across years, and $\varepsilon_{i, t}$ denotes the error term. We include dummies for gender, age, education, employment duration, temporary work, and wage percentiles. We pool all transitions of one year in the regression so that one worker can have multiple transitions within one year. Predicted average transition rates are then average population characteristics that we denote by $\bar{X}_{t}$ times the coefficient vector $\hat{\pi}_{e u, t}=\bar{X}_{t} \beta_{t}$. The predicted average separation rate corresponds by construction to the observed average rate. $^{31}$

Figure 13: Separation rates controlling for worker characteristics

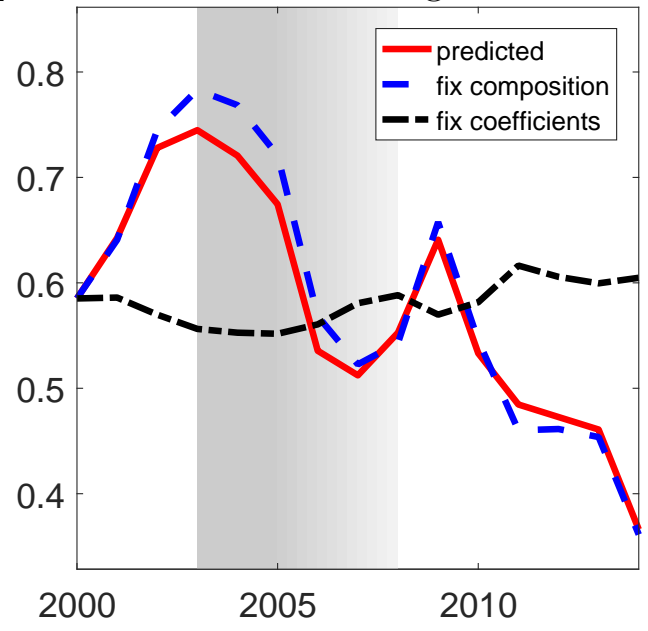

Notes: Yearly averages of monthly separation rates 2000-2014. The red solid line marks the predicted (actual) separation rate. The blue dashed line marks the separation rate keeping the composition of all observables fixed at their level in 2000. The black dotted line marks the separation rate keeping the coefficients of all observables fixed at their level in 2000. The grey area marks the period 2003 to 2005 when the Hartz reforms were enacted. The fading out indicates the first transition years 2006 to 2008 after the reforms.

We then construct two counterfactual transition rates. For the first counterfactual transition rate, we keep population shares at their level in 2000 and only vary coefficients over time $\tilde{\pi}_{e u, t}^{2000}=\bar{X}_{2000} \beta_{t}$. This captures changes in separation rates for a fixed population

\footnotetext{
${ }^{31}$ We pool all transitions within a year to compute the transition rates. This can lead to small deviations in comparison to an average of monthly rates, but in our case, the difference is negligible.
} 
of workers. Through the lens of our structural model in Section 3, these are changes in behavior, for example, due to changes in the UI system. For the second counterfactual transition rate, we keep coefficients at their level in 2000 and only vary population shares

over time $\check{\pi}_{e u, t}^{2000}=\bar{X}_{t} \beta_{2000}$. This captures the effects from changes in the composition of worker groups. Figure 13 shows the predicted separation rate $\hat{\pi}_{e u, t}$ (red solid line), the counterfactual transition rate with fixed population shares $\tilde{\pi}_{e u, t}^{2000}$ (blue dashed line), and the counterfactual transition rate with fixed coefficients $\check{\pi}_{e u, t}^{2000}$ (black dashed-dotted line). We find that the counterfactual transition rate with changes in coefficients $\beta_{t}$ tracks the drop in separation rates over time very closely. The counterfactual transition rate that keeps all coefficients fixed at their level in 2000 and where we only vary population shares over time hardly changes. This evidence strongly supports the idea that it was behavioral changes due to changes in the macroeconomic environment that explain the decline in the separation rate over time rather than changes in the composition of the workforce.

\section{C.3 Heterogeneity in transition rates by age groups}

This section provides further details on the heterogeneity in the changes in separation rates by age discussed in Section 2.4.2. Table 9 provides detailed information on separation rate changes by age and employment duration. The upper part of the table shows results for all workers and for three different age groups. Workers age 15-44 show the smallest decline in separation rates $(-14.2 \%)$ and workers in the age group from 45 to 64 years show the strongest decline in separation rates $(-25.2 \%)$. These age differences still hide important heterogeneity arising from employment duration. The lower part of Table 9 distinguishes workers by age and employment duration. Here, we find that changes in separation rates mirror the relative differences in changes in benefit eligibility from Figure 3. Short-term employed workers show across age groups a rather uniform decline in separation rates varying between $14.6 \%$ and $17.7 \%$. The decline is always less than the average decline over this time period of $22.0 \%$. We also find a much stronger decline for long-term employed workers age 45 and older. Their separation rates decline by $32.5 \%$ and $48.8 \%$. For younger long-term employed workers, we find a smaller decline. This is in line with the relative cut in benefits shown in Figure 3 that does not show any variation in the cuts in benefit eligibility among young workers. The larger decline among the oldest age group of long-term employed workers cannot be explained by the cut in benefit eligibility from Figure 3 alone. Looking at the longer-run trend in Figure 14(a) suggests that the likely explanation predates the Hartz reforms. The separation rates for the oldest group of workers seem to follow a longer-run downward trend starting in the mid-1990s. A detailed investigation of this trend is of independent interest but beyond the scope of this paper. We leave a detailed investigation of the reasons behind 
this trend to future research.

Table 9: Change in separation rates by employment duration and age

\begin{tabular}{lccc}
\hline & $1993-2002$ & $2008-2014$ & $\Delta \%$ \\
\hline age: $15-44$ & $0.72 \%$ & $0.61 \%$ & $-14.2 \%$ \\
age: $45-54$ & $0.43 \%$ & $0.35 \%$ & $-18.3 \%$ \\
age: $45-64$ & $0.46 \%$ & $0.35 \%$ & $-25.2 \%$ \\
\hline age: $15-44$, emp. duration $\leq 3$ years & $1.36 \%$ & $1.13 \%$ & $-16.8 \%$ \\
age: $15-44$, emp. duration $>3$ years & $0.26 \%$ & $0.22 \%$ & $-15.4 \%$ \\
age: $45-54$, emp. duration $\leq 3$ years & $1.47 \%$ & $1.25 \%$ & $-14.6 \%$ \\
age: $45-54$, emp. duration $>3$ years & $0.18 \%$ & $0.12 \%$ & $-32.5 \%$ \\
age: $45-64$, emp. duration $\leq 3$ years & $1.48 \%$ & $1.22 \%$ & $-17.7 \%$ \\
age: $45-64$, emp. duration $>3$ years & $0.27 \%$ & $0.14 \%$ & $-48.8 \%$ \\
\hline
\end{tabular}

Notes: Monthly separation rates before and after the Hartz reforms by employment duration and age. Column $\Delta$ reports the percentage change in rates from the period before the Hartz reforms to the period after the Hartz reforms. 
Figure 14: Separation and job finding rates by age

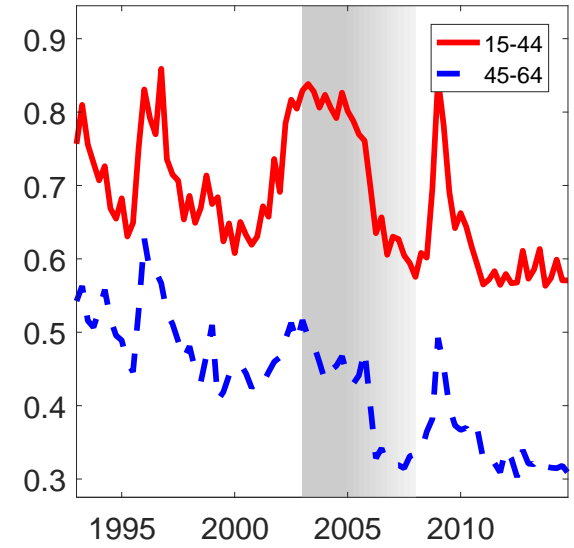

(a) Separation rate

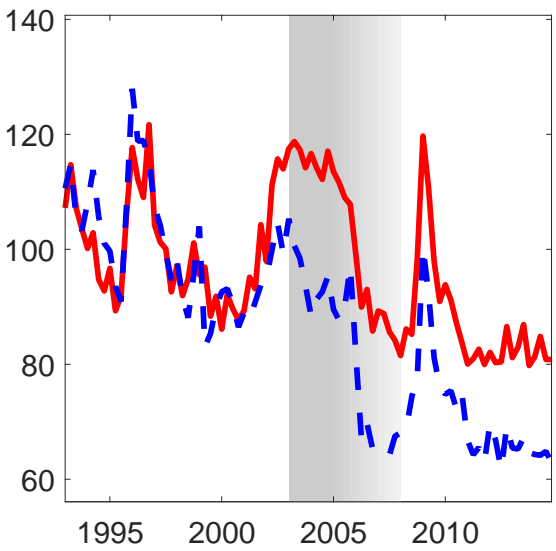

(b) Indexed separation rate

Notes: Separation rates for age groups 15-44 years (red solid lines) and 45-64 (blue dashed lines). The left panel shows the level of the separation rate. The right panel shows the change in the separation rate relative to its pre-reform level (1993-2002). The grey area marks the period 2003 to 2005 when the Hartz reforms were enacted. The fading out indicates the first transition years 2006 to 2008 after the reforms.

\section{C.4 East Germany}

For our empirical analysis in Section 2.3, we exclude workers who have employment or unemployment spells in East Germany. We do this to abstract from any effects of a transition of the East German labor market in the decade after reunification. In this section, we explore separation and job finding rates for East Germany starting in 1995. Figure 15 shows the time series for separation rates and job finding rates for East German workers and applies the inflow correction described in Section 2.2. The corresponding results for the West German labor market are in Figure 2.

Separation rates in East Germany are higher than in our baseline West German sample. Before the reform, the monthly separation rate is slightly higher than 1.4\%. Figure 15(a) shows that separation rates in East Germany plummet in 2006 to $70 \%$ of their pre-reform level and in 2014 stand at $50 \%$ of their pre-reform trend. The data suggest that there is an ongoing falling trend in the separation rate. Hence, the decline in the separation rate is stronger in the East than in the West German labor market. Regarding job finding rates, the results are even more striking. Relative to their pre-reform level of $5.4 \%$, the job finding rate in the East German labor market stands in 2014 at its pre-reform level. All changes in East German unemployment result therefore from a decline in separation rates, thereby further reinforcing our findings from the West German labor market.

Figure 16 provides results on the heterogeneity in the changes in separation rates for the 
Figure 15: Changes in separation and job finding rates East Germany (1995 - 2014)

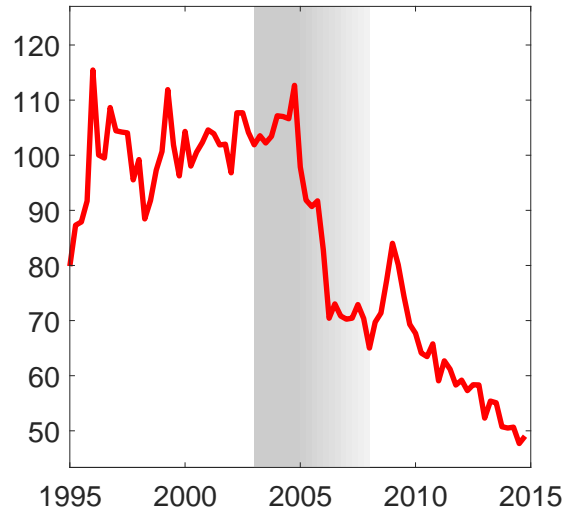

(a) Separation rate (indexed)

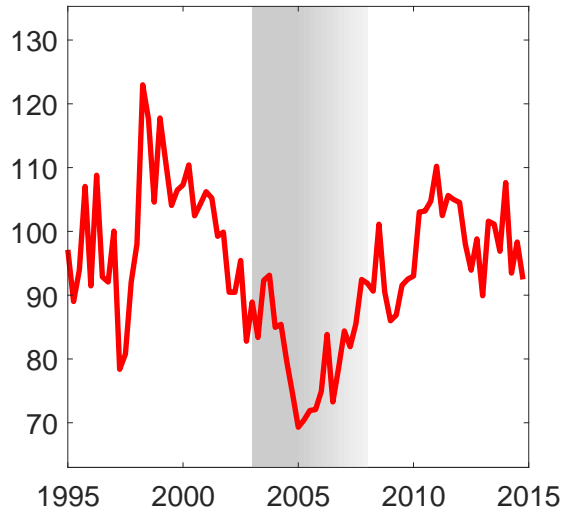

(b) Job finding rate (indexed)

Notes: Separation and job finding rates for East Germany 1995-2014. Both series have been indexed to their pre-reform level (1995-2002). Both series exclude non-employed entering the unemployment pool in the first half of 2005 who did not become employed until the end of 2006 (inflow correction). The grey area marks the period 2003 to 2005 when the Hartz reforms were enacted. The fading out indicates the first transition years 2006 to 2008 after the reforms. Data are quarterly averages of monthly rates.

East German labor market over time. The corresponding results for the West German labor market are shown in Figure 4.

The changes in separation rates by age and employment duration in the East German labor market corroborate the findings for the West German labor market. We find that long-term employed workers show a much stronger decline than short-term employed workers (Figure 16(a)). Looking at workers in the age range from 15 to 44 years in Figure 16(b), we find a roughly equal decline by $50 \%$ from the pre-reform period to 2014 . The short-term employed typically show a slightly smaller decline than the long-term employed but also started from a higher level in 2005. For workers in the age group 45-64 years, we find a much stronger decline for the long-term employed in line with our results for the West German labor market (Figure 16(c)). Separation rates for the longterm employed workers decline roughly $20 \%$ more than those for the short-term employed workers. The average decline in East Germany is larger. Finally, when comparing shortterm employed workers in the age group 15-44 years to workers in the age group 45-64, we find again, as in the case of the West German labor market, that their separation rates lie virtually on top of each other and decline in lockstep between 2005 and 2014 (Figure 16(d)). 
Figure 16: Separation rates by age and employment duration (1993 - 2014) East Germany

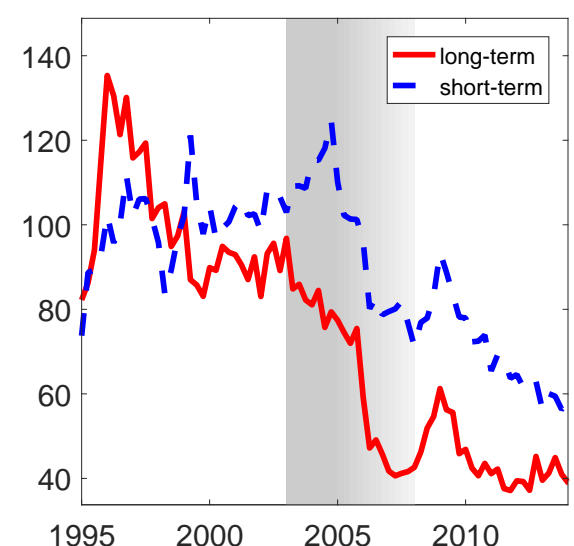

(a) all workers

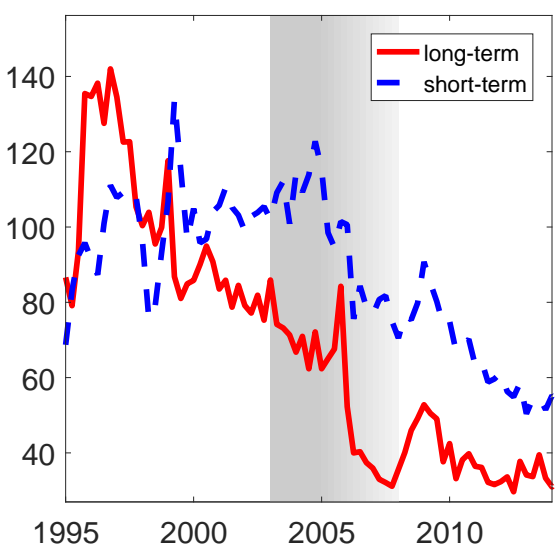

(c) age $45-64$

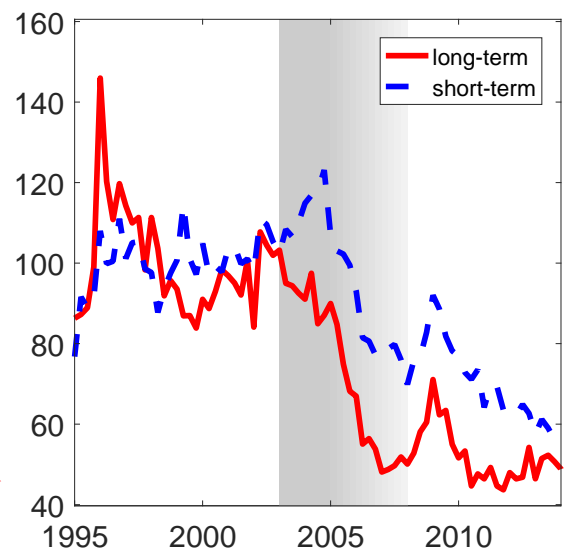

(b) age $15-44$

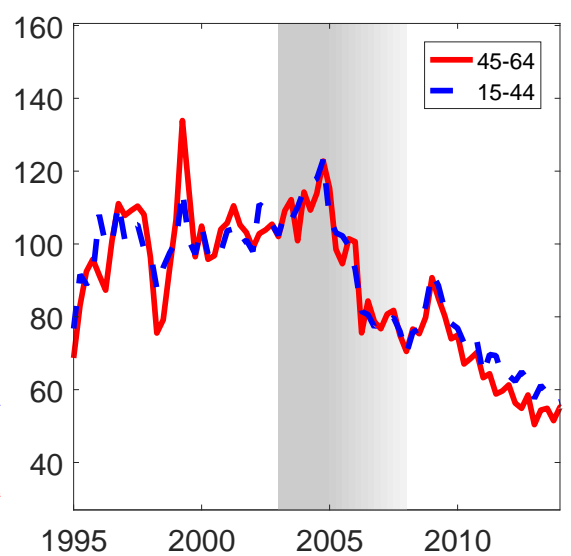

(d) short-term employed

Notes: Separation rates by employment duration and age for East Germany 1995 - 2014, indexed to their pre-reform level (1995-2002). The red solid lines in panels (a)-(c) mark the separation rate for long-term employed workers who were continuously employed for three years or more. The blue dashed lines in panels (a)-(c) mark the separation rate for short-term employed workers with at most three years of continuous employment. Panel (d) shows the separation rate for short-term employed workers separately for young (age 15-44, blue dashed line) and old employees (age 45-64, red solid line). The gray area marks the period 2003 to 2005 when the Hartz reforms were enacted. The fading out indicates the first transition years 2006 to 2008 after the reforms. Data are quarterly averages of monthly rates. 


\section{C.5 Including marginally employed}

For our baseline sample, we do not define workers as employed if their only employment relationship is under a marginal employment contract. As described in Section B.2 of this appendix, we count these persons as either unemployed or out of the labor force depending on whether or not they have a parallel unemployment spell in that month. A main reason for excluding marginal employment in our baseline sample is to derive consistent time series for worker flows. Information on marginal employment becomes comprehensive in the microdata after 1999 so that we cannot construct a consistent time series going back to 1993. Before 1999, information on marginal employment is typically not recorded. As a sensitivity analysis, we include all available information on marginal employment when defining employment states. Figure 17 shows the separation rates and job finding rates including marginal employment information in comparison to the rates from the baseline sample.

Figure 17: Separation and job finding rates including marginal employment

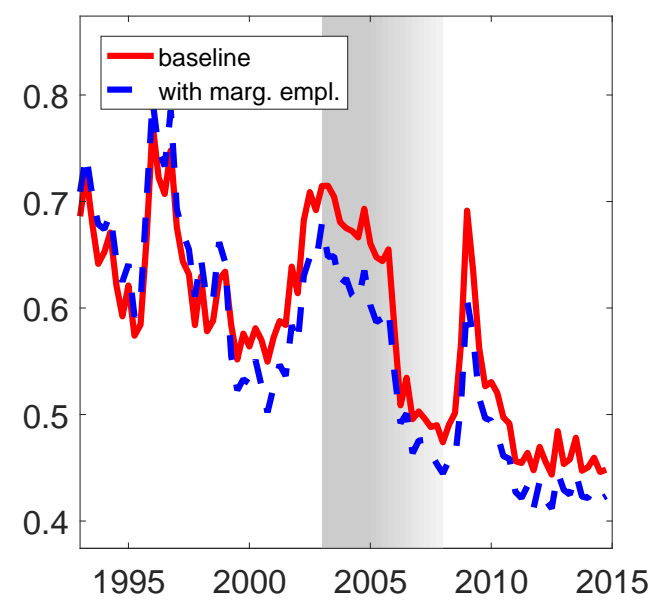

(a) Separation rates

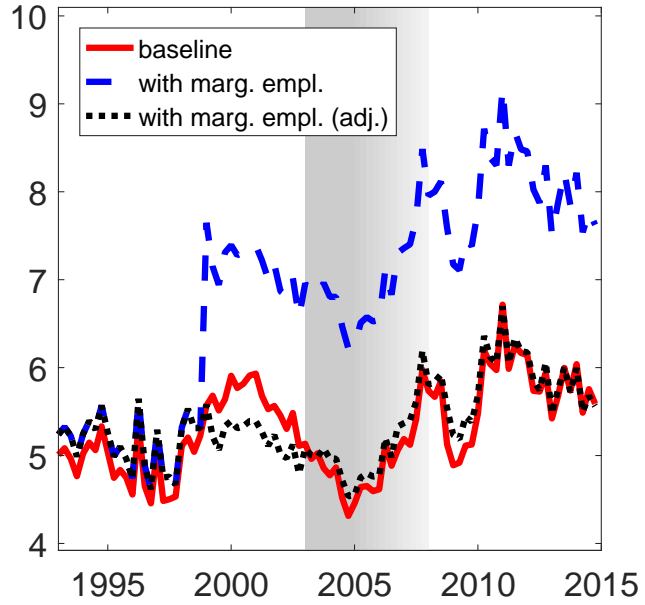

(b) Job finding rates

Notes: Separation rates and job finding rates in West Germany 1993-2014 for the baseline sample (red solid line) and for a sample where marginal employment is included in the employment definition (blue dashed line). The black dotted line in the right panel shows the job finding rates including the marginally employed adjusted for the structural break in 1999. The grey area marks the period 2003 to 2005 when the Hartz reforms were enacted. The fading out indicates the first transition years 2006 to 2008 after the reforms.

Figure 17(a) shows separation rates for the baseline sample (red solid line) and the sensitivity sample including marginal employment information (blue dashed line). Marginal employment accounts only for a small fraction of total employment so that the change in aggregate separation rates is small. The decline in separation rates becomes slightly more pronounced in the sensitivity sample and including marginal employment would lead to 
a larger decline of separation rates compared to the baseline sample. Figure 17(b) shows job finding rates from the baseline sample (red solid line) and sensitivity sample (blue dashed line). The job finding rate in the sensitivity sample shows a structural break in 1999 when complete information on marginal employment becomes available. We provide an additional estimate for the sensitivity sample, where we remove the structural break by removing the level shift (black dotted line). ${ }^{32}$ We find that after we remove the structural break in 1999, the job finding rates from the baseline and sensitivity sample track each other closely. If anything, the job finding rate in the adjusted sensitivity sample is slightly higher before 1999, implying a slightly smaller increase in job finding rates after the reform. We conclude that our empirical findings on the importance of the decline in separation rates are robust to a change in the employment definition to include marginal employment information.

\section{C.6 Effect of active labor market policy}

Section 2.2 discusses changes in regulation for unemployment registration and the inflow correction to adjust for this change. A second change that affects the microdata records and was enacted as part of the Hartz reforms was the treatment of active labor market programs. Starting in 2005, unemployed persons who participate in training programs, internships, or other measures that are part of active labor market policy are no longer recorded as unemployed in the microdata while they are taking part in such programs. Our baseline definition of employment states assigns workers in active labor market programs as out of the labor force. If these workers go from a program to regular employment, the baseline sample would not count this as a transition from unemployment to employment; as a consequence, the job finding rate would be lower. To explore the quantitative effect of this change in recording, we exploit the information from the unemployment records that provide a reason for why the worker is no longer registered as unemployed. We exploit this information to identify workers who participate in active labor market programs and explore how our estimates for job finding rates are affected if we include workers as unemployed while they are in active labor market programs. Figure 18 shows the unemployment rate and the job finding rate for the baseline sample and for the sensitivity sample that still counts all participants in measures of active labor market programs after 2005 as unemployed if they were unemployed before the program started. ${ }^{33}$

Looking at the unemployment rate in Figure 18(a), we find a very small increase in

\footnotetext{
${ }^{32}$ The level shift at the structural break corresponds to a $37 \%$ increase in the job finding rate in the sensitivity sample.

${ }^{33}$ Due to the inflow correction, the samples differ slightly before 2005 .
} 
Figure 18: Unemployment and job finding rates including active labor market programs

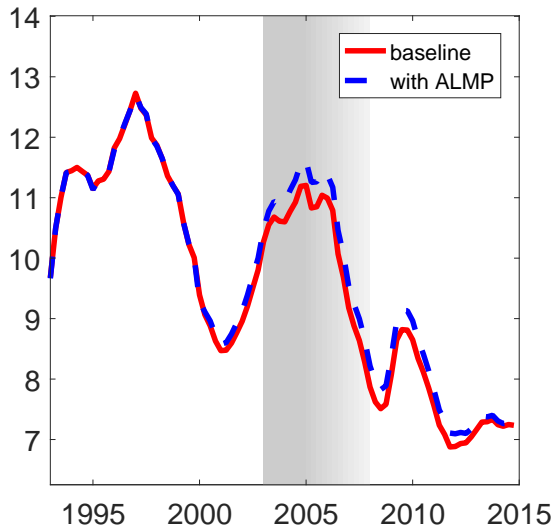

(a) Unemployment rate

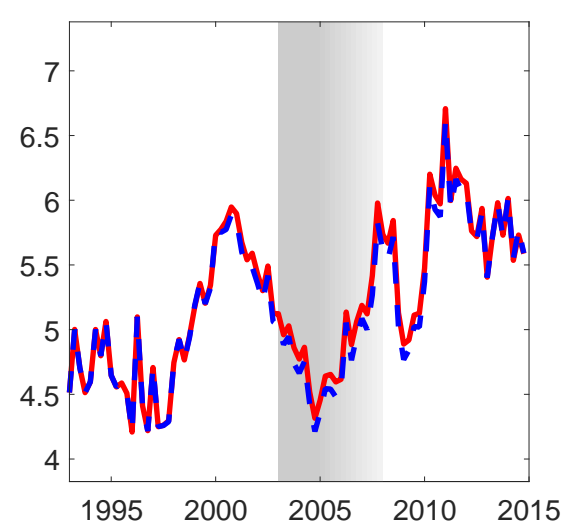

(b) Job finding rate

Notes: Unemployment and job finding rates from the baseline sample and a sensitivity sample that includes workers in active labor market policy (ALMP) programs in the group of the unemployed. See text for further details. The grey area marks the period 2003 to 2005 when the Hartz reforms were enacted. The fading out indicates the first transition years 2006 to 2008 after the reforms.

unemployment, yet the effect is negligible. Job finding rates in Figure 18(b) are hardly affected. We conclude that the change in the recording of active labor market programs in the microdata has a quantitatively negligible effect on our results.

\section{Economic activity in Austria and Germany}

Section 4.3 contrasts the actual performance of the German labor market and a counterfactual performance absent the Hartz reforms with the Austrian experience. We choose Austria as a comparison because of its close business-cycle comovement with the German economy. Figure 19 demonstrates this close comovement over the two decades considered in the counterfactual simulation from 1993 to 2014. As in the main part of the paper, we use GDP per capita to trace out the business cycle. We transform GDP per capita by taking the logarithm and we extract the cyclical component using an Hodrick-Prescott filter with smoothing parameter $\lambda=100$. We find a very high correlation and also very similar volatility of the business cycle over time. 
Figure 19: Cyclical component of GDP for Germany and Austria (1993-2014)

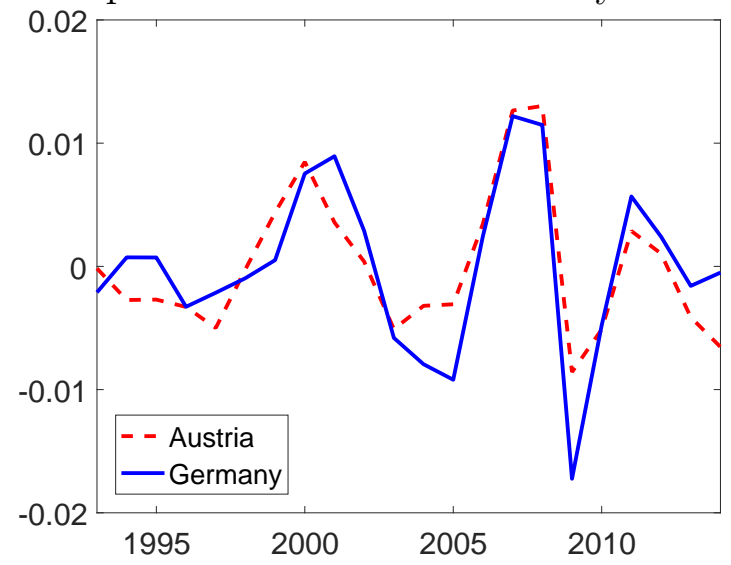

Notes: Cyclical component of annual GDP per capita for Austria and Germany for the period 1993-2014. GDP per capita is transformed to log and the cyclical component is extracted using an HP filter with smoothing parameter $\lambda=100$.

\section{E Alternative explanations}

The German labor market miracle has received a lot of attention in the public debate as many European countries struggle with high unemployment rates and the question arises whether Germany can serve as a role model for these countries. Our paper provides new empirical evidence, together with a causal explanation based on economic theory that the UI reforms that were part of the Hartz reforms in the mid-2000s are responsible for the German labor market miracle. Other explanations for the German labor market miracle have been proposed and we discuss three of the most prominent alternative explanations in this section. A prominent idea put forward by Dustmann et al. (2014) is falling unit labor costs in Germany relative to its European neighbors. In Section E.1, we look at changes in unemployment rates and unit labor costs in a cross-section of European countries to explore this idea. A closely related explanation is an export-driven boom in the labor market due to demand from China and other European countries. In Section E.2, we compare worker flows in export industries to those that produce for the domestic market. Finally, section E.3 looks at the composition of unemployment and the share of long-term unemployed. One goal of the Hartz reforms was to reduce long-term unemployment and that might have contributed to a decline in unemployment after the reforms.

\section{E.1 Unit labor costs}

One prominent narrative of the German labor market miracle comes from Dustmann et al. (2014), who link the German labor market miracle to a decline in Germany's unit labor 
cost and wages relative to other European countries. Figure 20 shows the ratio of German unit labor costs (ULC) (red solid line) and unemployment rate (blue dashed line) relative to other European countries. ${ }^{34}$ We find that the relative decline of Germany's ULC had already started in the 1990s, long before the Hartz reforms were enacted. The idea behind how changes in ULC are related to changes in unemployment rates is that with falling ULC production became relatively cheaper in Germany, thereby increasing labor demand in Germany at the cost of falling labor demand in other European countries. As a result, stronger labor demand leads to declining unemployment rates in Germany, and in comparison, unemployment rates in other European countries with weakened labor demand rise. The relative unemployment trends in Figure 20 paint a different picture. During the period when German ULC were falling relative to other European countries, its unemployment rate was rising in comparison to these countries, whereas the fall in unemployment rates between 2005 and 2014 was accompanied by stagnating or even increasing relative ULC in Germany. Without drawing causal conclusions, these negatively correlated time series are intricately reconciled with the hypothesis that declining ULC were the main driver of the German labor market miracle.

\section{E.2 Export demand}

Related to the idea of falling unit labor costs in Germany relative to its European competitors is the idea that rising export demand for German goods has spurred labor demand in the German labor market and has led to a decline in separation rates contemporaneously with the labor market reforms. To investigate this idea, we follow Dauth et al. (2016) and classify industries by their export or import exposure. If labor demand from abroad is a key driver of the labor market miracle, we expect separation rates to decline in the export-exposed industries relative to import-exposed or unexposed industries. We adopt the classification of import- and export-exposed industries from Dauth et al. (2016). Their classification follows the methodology used in the seminal paper by Autor et al. (2013) on the impact of Chinese import competition on industries in the United States. Import exposure is defined as the absolute value of trade flows into an industry from a particular region relative to the trade flows into that industry stemming from all countries; export exposure is defined equivalently. Dauth et al. (2016) classify 93 industries at the 3-digit level in the SIAB sample. Out of these industries, they report the 25 most import-exposed and the 25 most export-exposed industries in Table A.2 of their appendix. We take the classification from this table to define the import-exposed

\footnotetext{
${ }^{34} \mathrm{EU}-18$ is the employment-weighted average of $18 \mathrm{EU}$ countries: Austria, Belgium, Czech Republic, Denmark, Estonia, Finland, France, Hungary, Ireland, Italy, Luxembourg, Netherlands, Norway, Poland, Portugal, Slovakia, Spain, and the UK.
} 
Figure 20: Unit labor costs and unemployment rates in the EU

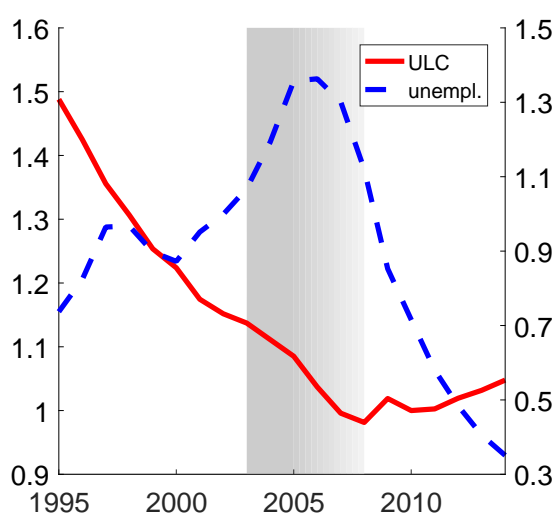

(a) EU 18

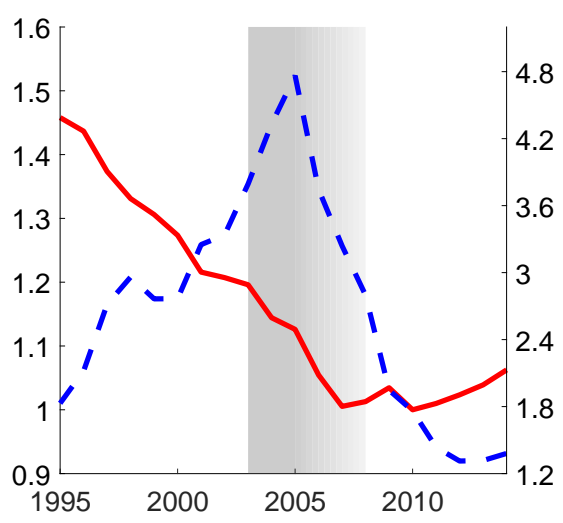

(c) UK

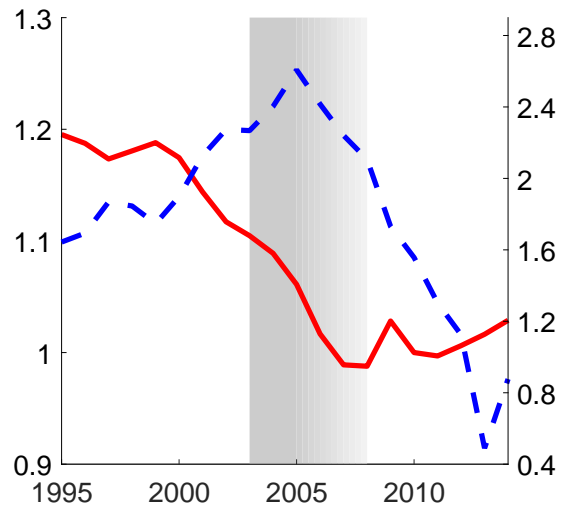

(b) France

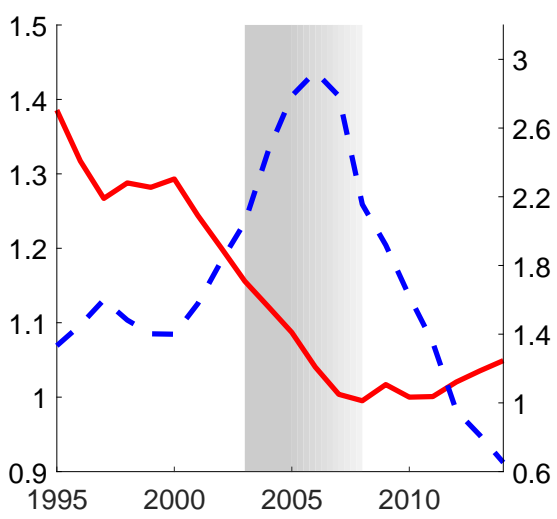

(d) Italy

Notes: The red solid lines (left axis) show ULC in Germany divided by ULC in other European countries. The blue dashed lines (right axis) show the German unemployment rate relative to the unemployment rate in these countries. The grey area marks the period 2003 to 2005 when the Hartz reforms were enacted. The fading out indicates the first transition years 2006 to 2008 after the reforms.

and export-exposed industries in our sample.

Table 10 shows the decline in separation rates across industries with no trade exposure, with export exposure, and with import exposure. Industries with neither import nor export exposure show a decline in separation rates from the pre-reform to the post-reform period of $20 \%$, close to the average decline of $22 \%$. We find that both import-exposed and export-exposed industries show much stronger declines relative to other industries. Separation rates in trade-exposed industries decline by more than $40 \%$. The effect on the overall separation rates remains modest, however, because employment shares of these industries are small and account for less than $10 \%$ of employment. Furthermore, the declines in the import-exposed and export-exposed industries are about the same size so that export-induced demand as a driver of the decline in separation rates seems at odds 
Table 10: Change in separation rates by trade exposure

\begin{tabular}{lccc}
\hline industries & $1993-2002$ & $2008-2014$ & $\Delta \%$ \\
\hline all & $0.63 \%$ & $0.49 \%$ & $-22.0 \%$ \\
no exposure & $0.63 \%$ & $0.50 \%$ & $-20.0 \%$ \\
export exposure & $0.44 \%$ & $0.26 \%$ & $-40.8 \%$ \\
import exposure & $0.62 \%$ & $0.34 \%$ & $-44.4 \%$ \\
\hline
\end{tabular}

Notes: Monthly separation rates before and after the Hartz reforms by trade exposure. Column $\Delta$ reports the percentage change in rates from the period before the Hartz reforms to the period after the Hartz reforms.

with the observed pattern. The evidence therefore does not support a prominent role for export-driven labor demand as an explanation for the German labor market miracle.

\section{E.3 Long-term unemployment}

One goal of the Hartz reforms was to reduce long-term unemployment. To explore whether the reduction in long-term unemployment was an important driver behind the reduction in overall unemployment, we examine the composition of the unemployment pool over time. If the Hartz reforms increased, in particular, job finding rates of longterm unemployed, this should have shifted the composition of the unemployment pool toward short-term unemployment after the reforms. Figure 21 shows that apart from a spike during the Great Recession between 2006 and 2008, the share of unemployed who have been out of work for more than one year did not change relative to the pre-Hartz period.

The analysis in Section 4 provides evidence that higher job finding rates are not the main reason for the decline in the unemployment rate after 2005. The fact that we find a largely constant share of long-term unemployed after the Hartz reforms implies that there have also been no differential effects among the unemployed and a stronger increase in job finding rates among the long-term unemployed. 
Figure 21: Share of long-term unemployed in Germany (1998-2015)

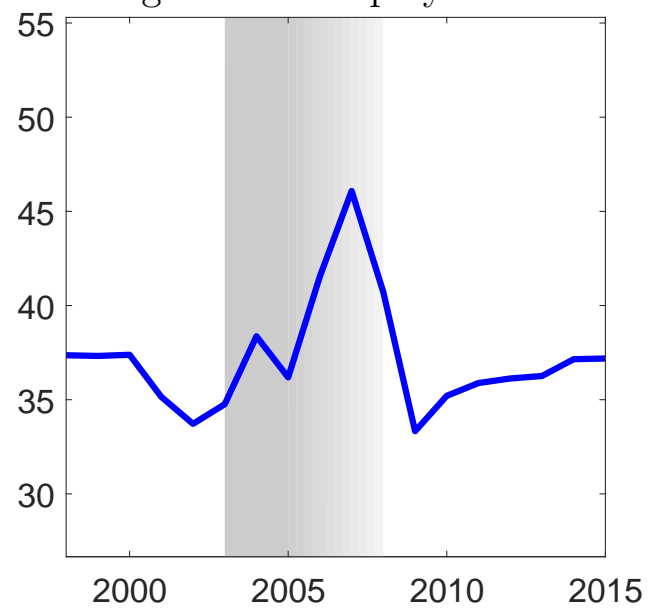

Notes: Share of long-term unemployed (more than 12 months) in total unemployment. The grey area marks the period 2003 to 2005 when the Hartz reforms were enacted. The fading out indicates the first transition years 2006 to 2008 after the reforms. 